\title{
LAS SAYWAS DEL INKA EN EL DESIERTO DE ATACAMA: ¿UNA INSCRIPCIÓN DEL CALENDARIO EN EL QHAPAQ ÑAN?
}

\author{
INKA SAYWAS IN THE ATACAMA DESERT: INSCRIPTIONS OF THE INKA \\ CALENDAR ALONG THE QHAPAQ NAN?
}

Ceclila Sanhueza ToháA

Se presentan y analizan desde un punto de vista etnohistórico y arqueoastronómico las llamadas saywas del Inka del Qhapaq Nan del desierto de Atacama (Región de Antofagasta, Chile). A partir de dos casos muy diferentes (Lasana y Tocomar), se sostiene que estas columnas o "tupus" estaban estrechamente vinculadas al culto solar estatal y a determinadas fechas del calendario inkaico. Se complementan diversas metodologías que permiten demostrar que las saywas -que responden al mismo nombre que las columnas astronómicas del Cuzcocumplían también la función de medir el tiempo, indicando la salida del sol en hitos calendáricos tan relevantes como los solsticios, pero esta vez situándose no ya en puntos estratégicos de la capital del Imperio, sino en el propio Camino del Inka.

Palabras clave: Qhapaq Ñan, saywas, arqueoastronomía, Región de Antofagasta, Inka.

Inka saywas (roadside cairns) found along the Qhapaq Nan in the Atacama desert (Antofagasta Region, Chile) are presented and analyzed here from an ethnohistorical and archeoastronomical perspective. Examining two very different cases (Lasana and Tocomar), the authors argue that these cairns (also called tupus) were closely linked to the state-sponsored cult of the sun and to specific dates in the Inka calendar. Here, complementary methodologies are applied to prove that the saywas -the term used also for certain astronomical columns found in Cuzco-were also used for measuring time, indicating the sunrise on very important dates such as the solstice, in this case not at strategic points in the capital, but on the Inca Road itself.

Keywords: Qhapaq Nan, saywas, archeoastronomy, Antofagasta Region, Inka.

\section{QHAPAQ ÑAN: EL CAMINO "AMOJONADO" Y "MEDIDO"}

Según las fuentes coloniales, cuando el Inka tomaba posesión de una nueva provincia, "medía", "amojonaba" y "repartía" sus territorios y recursos, reordenando el espacio social y productivo (Betanzos 1987 [1551]; Sanhueza 2004). Así también, los Caminos del Inka fueron descritos por viajeros y cronistas como un complejo sistema vial "amojonado" y "medido" a partir de patrones de medición que, traducidos a categorías hispanas, se denominaron leguas del Inca (Cieza de León 1986 [1553]; González Holguín 1952 [1608]; Bertonio 1984 [1612]; Guamán Poma 1992 [1615]).

En una publicación anterior (Sanhueza 2004), propusimos posibles interpretaciones de las categorías de medición aplicadas y sus significaciones de carácter espacial, temporal, social y ritual. Desde esa perspectiva, podemos señalar que los caminos estaban organizados y medidos a partir de criterios relativos, que no correspondían a unidades rígidas de medición, aplicando una lógica similar a las que se utilizaban en las mediciones de superficies o espacios productivos, frecuentemente llamados tupus. Sus dimensiones variaban según una serie de factores combinados que organizaban o "medían"

\footnotetext{
A Cecilia Sanhueza Tohá, Investigadora asociada Universidad Bernardo O’Higgins, Centro de Estudios Históricos, Fábrica 1990, Santiago. Museo Chileno de Arte Precolombino, Bandera 361, Santiago, email: csanhueza@hotmail.com
} 
el desplazamiento en los Andes, tales como distancia, tiempo, energía humana aplicada y prácticas rituales asociadas, entre otros (Sanhueza 2004). ${ }^{1}$

Guamán Poma (1992 [1615]: 327) define el Qhapaq Nan como un camino cuyas distancias estaban medidas y señalizadas: "con su legua y medida amojonado y señalado". Sin embargo, no atribuye a esa legua una extensión determinada, aunque en su ilustración sobre los caminos reales destaca la presencia de columnas de piedra asociadas a las rutas (fig. 1). De acuerdo a los vocabularios coloniales, estas columnas se conocían principalmente con el nombre de saywa, y estaban asociadas tanto a la medición de espacios o superficies como a la de distancias de camino.

Sayhua: Mojón de tierras.

Sayhuani sayhuacuni: amojonar tierra hacer linderos (González Holguín 1952 [1608]).

Chuta, Sayhua: Término en cada cien braças de tierra en quadro, y señal de las leguas.

Chutatha, sayhuatha: Ponerle y señalar las leguas de camino, como hazían en tiempo del Inga (Bertonio 1984 [1612]: $319,288)$.

Por otra parte, estas saywas pudieron operar como deslindes de territorios, provincias o suyus de mayor o menor envergadura y jerarquía (Murúa 2004 [1590]; Guamán Poma 1992 [1615]: 325, 847). Es decir, podían representar fronteras importantes, como hemos postulado en el caso de Vaquillas, en el borde sur de la cuenca del salar de Punta Negra (Sanhueza 2005); como también deslindar territorios menores, o incluso segmentar localmente la vía para labores comunitarias de reparación y mantención del camino (Cieza de León 1986 [1553]: 41-42; Lynch 1995-1996: 191-192; Sanhueza 2004; Berenguer 2007).

En definitiva, el término medir parece ser la traducción española a una serie de prácticas de distribución del espacio social y productivo, así como de organización del desplazamiento y las comunicaciones en un extensísimo territorio. Sostenemos que las columnas de los caminos incaicos, llamadas frecuentemente tupus por los españoles, pero cuya denominación específica era saywa, estarían dando cuenta de diferentes sistemas de marcación y medición del espacio, relacionados con la organización de territorialidades y con la medición de distancias (Sanhueza 2004). Sin embargo, como expondremos a continuación, hemos podido comprobar que, al menos en ciertos casos, las saywas del Inka estaban

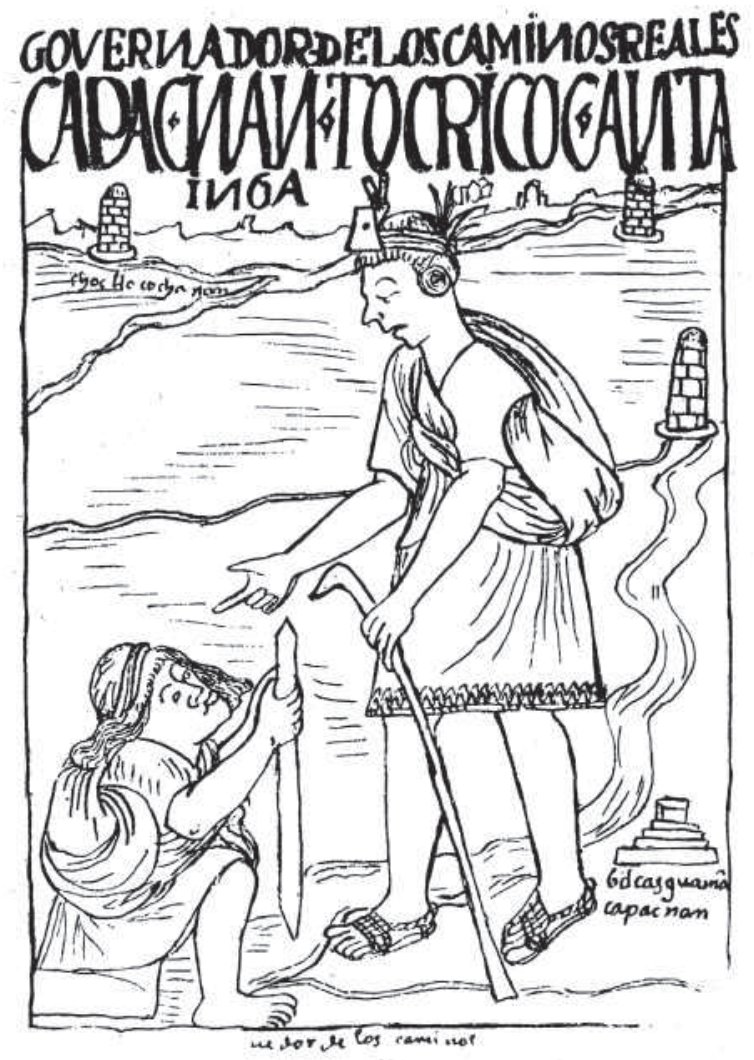

Figura 1. El Qhapaq Ñan y sus columnas según la ilustración de Guamán Poma de Ayala (1992 [1615]). Figure 1. The Qhapaq Nan and its columns in an illustration of Guamán Poma de Ayala (1992 [1615]).

también estrechamente asociadas al culto solar y a la medición del tiempo calendárico.

En efecto, al menos en algunos casos, las sayhuas del Qhapaq Ñan operaban como indicadores astronómicos y calendáricos. Antes de exponer estos avances de la investigación, se hace necesaria una breve descripción y discusión respecto a los antecedentes astronómicos del valle del Cuzco.

\section{ASTRONOMÍA INKA EN LA METRÓPOLI. ANTECEDENTES GENERALES}

\section{El circuito anual del sol, la caminata celeste}

El circuito aparente del sol en el cielo representaba una serie de acontecimientos de profunda significación simbólica, cosmológica y calendárica. Cada ciclo simbolizaba 
el recorrido que hacía Inti en el cielo durante el año. Los solsticios pueden definirse como los momentos en que el sol llega a los puntos extremos (al norte o al sur) de su movimiento aparente con respecto a la línea ecuatorial. A partir de allí comienza a "devolverse" para completar su circuito anual. Este momento del calendario andino es entendido y percibido hasta la actualidad como un período (que puede abarcar algunos días) en que el sol "se detiene" en el cielo para luego recomenzar su regreso (Urton 1981: 488; Castro \& Varela 2004: 295). Los solsticios eran simbolizados en la tradición oral incaica como aquellos momentos en que el sol se "sentaba en su silla", donde permanecía unos días detenido para comenzar luego a "caminar sin descansar" en sentido contrario (Guamán Poma 1992 [1615]: 830). Es decir, de acuerdo a su movimiento aparente, el sol "caminaba" desde su silla en el sur (solsticio de verano en el hemisferio sur), hasta su silla en el norte (solsticio de invierno), y de allí se devolvía nuevamente, pasando por la línea equinoccial describiendo un círculo virtual (Zuidema 1966: 25). En su recorrido anual, agrega Guamán Poma (1992 [1615]: 830), el sol tenía también una "silla" en cada "grado" del cielo, cada una de las cuales representaba los meses andinos.

Estos relatos tenían profundas repercusiones en la actividad productiva y ceremonial del Estado Inka. El calendario cuzqueño combinaba los ciclos solares (solsticios y equinoccios) con los meses y ciclos lunares y con la observación de los movimientos siderales. La observación astronómica permitía establecer y calcular el calendario estatal, señalando así no solo los hitos significativos de la actividad económica, sino también las importantes festividades y rituales asociados a ellos (Zuidema 1989: 402-407). Para ello, los inkas se valían de diferentes instrumentos de medición astronómica.

\section{El Ushnu}

Uno de los principales dispositivos astronómicos de la ciudad del Cuzco y, en general, de las capitales o centros administrativos de las provincias, era el ushnu. En sus orígenes, estas estructuras habrían tenido una función ritual dirigida básicamente a la recepción de ofrendas en determinadas ceremonias (Zuidema 1989). Sin embargo, durante el proceso de expansión, el ushnu se fue complejizando, adecuándose a las necesidades imperiales. Su estructura se fue sofisticando arquitectónicamente, adoptando el aspecto de plataforma, e incorporando un conjunto de elementos asociados a la actividad política, a la ritualidad y a la astronomía (Pino 2005).

Los cronistas suelen describir el ushnu de maneras muy distintas, definiéndolo como "pilar", "columna", "mojón", "piedra hincada", "bolo", "trono" o "asiento del Inca," "tribunal", "altar", "escaño", "estrado", "placeta”, "pila” o "fuente" (González Holguín 1952 [1608]: 358; Garcilaso de la Vega 1995 [1609]: 590-591; Santa Cruz Pachacuti 1993 [1613]; Guamán Poma 1992 [1615]: 239; Zuidema 1989: 402-454). Los investigadores sostienen que esta curiosa diversidad de definiciones está refiriendo a diferentes aspectos y funcionalidades asociados al ushnu, como también al conjunto de dispositivos que podían conformarlo según las necesidades específicas de cada ceremonial (Zuidema 1989; Zecenarro 2001: 184-186). Entre estas funcionalidades, este altar, pila o placeta, era por excelencia el lugar del sacrificio a la divinidad (Zuidema 1989: 425-430). Pero, en su acepción de "pilar", "columna", "piedra hincada" o "bolo", era un gnomon, es decir, un instrumento utilizado para observar y calendarizar los movimientos del sol, la luna y las estrellas. ${ }^{2}$ En ese sentido, se podía tratar de un elemento fijo, como una columna, o movible, a veces un ídolo de fina confección, o un pilar o bolo de oro; otras veces parece haber sido un palo o una sencilla pieza lítica de estructura alargada y recta, que se hincaba verticalmente sobre una base fija de la plataforma o de una columna cuando se requería su función astronómica (Betanzos 1987 [1551]: 51-52; Guamán Poma 1992 [1615]: 214; Zuidema 1989: 408-412; Zecenarro 2001). El gnomon indicaba la posición de los astros celestes, principalmente el sol en su recorrido anual, su paso por el cenit y anticenit; y permitía predecir y calcular los puntos de salida y puesta del sol, así como la proximidad de los solsticios y equinoccios. Cuando el sol en su cenit dejaba de proyectar sombra al mediodía sobre el gnomon (evento que se da en diferentes fechas según la latitud correspondiente), era un momento, según la tradición oral cuzqueña, en que la divinidad "se sentaba" también en la tiana o asiento del sol, simbolizada por uno de los elementos constitutivos del ushnu: el escaño, según Zuidema (1989: 409-411), una columna o el propio gnomon según Zecenarro (2001: 185).

Por otra parte, la estructura del ushnu en su conjunto era entendida como un mirador, es decir como un punto central desde el cual se establecían líneas de mira o virtuales ejes de orientación hacia el horizonte, utilizando como referente la disposición de los ceques y 
huacas, tanto para la observación y medición astronómica (cuando esta última coincidía con un ceque), como para la organización espacial de la arquitectura urbana del Cuzco. En ese sentido, el ushnu era un elemento ordenador del tiempo y el espacio (Zuidema 1989: 430-445).

No obstante, el ushnu también tenía una gran importancia como símbolo y emblema del poder político. Era el "trono y aciento de los Yngas", emulando a la divinidad solar, y cumplía la función de "tribunal", desde donde se administraba justicia (González Holguín 1952 [1608]: 358, 684; Zuidema 1989: 445-452). Es decir, la función astronómica y la política estaban estrechamente vinculadas.

\section{Las columnas astronómicas del valle del Cuzco según las fuentes coloniales}

Diferentes cronistas y autores contemporáneos han descrito, analizado o discutido la función astronómica de las columnas del valle del Cuzco (Cieza de León 1973 [1550]; Betanzos 1987 [1551]; Anónimo 1906 [15701584]; Sarmiento de Gamboa 1942 [1572]; Garcilaso de la Vega 1995 [1609]; Cobo 1964 [1653]; Zuidema 1966, 1989, 2010; Zuidema \& Urton 1976; Bauer \& Dearborn 1998; Zecenarro 2001; Williams 2001, entre otros).

Aparentemente, la estructura de estos pilares podía ser de mayor o menor complejidad y tamaño, correspondiendo desde "pequeñas torrecillas" (Cieza de León 1973 [1550]), hasta grandes columnas como las que describen Betanzos (1987 [1551]: 74), Sarmiento (1942 [1572]: 93) y Garcilaso de la Vega (1995 [1609]: 93), entre otros. Estas estructuras permitían "medir" los movimientos aparentes del sol (salidas y puestas), de la luna y de determinadas constelaciones y estrellas; calcular la llegada de los solsticios y equinoccios y calendarizar las actividades productivas y rituales del año (Cobo 1964 [1653]: 141-142; Zuidema 1989: 408-412; Bauer \& Dearborn 1998; Williams 2001).

Hay distintas, e incluso, contradictorias versiones en las fuentes respecto a la ubicación, tamaño y cantidad en que podían presentarse estas columnas. Betanzos (1987 [1551]: 74) describe cuatro grandes pirámides o "relojes" y señala que Inca Yupanqui las había mandado instalar para observar a través de ellas los movimientos solares y lunares, "los cuales relojes hizo en esta manera que todas las mañanas e tardes miraba el sol en todos los meses del año mirando los tiempos del sembrar y coger y ansi mismo cuando el sol se ponía y ansi mismo miraba la luna cuando era nueva e llena e menguante, los cuales relojes hizo hacer de cantería encima de los cerros más altos a la parte do el sol salía y a la parte do se ponía". Estas columnas podían alcanzar "dos estados de altura" $y$ su objetivo, agrega el cronista, era que "la gente común" reconociera el tiempo de sembrar y de cosechar. ${ }^{3}$ Por su parte, Cobo (1964 [1653]: 142) describe en forma más detallada la utilización de "pilares" para medir el tiempo y predecir eventos importantes del año. Señala que existían dos pilares al oriente y otros dos al poniente de la ciudad, por donde salía y se ponía el sol cuando llegaba a los trópicos y: "al tiempo que salía y se ponía en derecho de los pilares de la banda del sur, mirando desde la dicha ciudad, tenía por principio el año". Distingue además otros pares de pilares distribuidos en los entornos de la ciudad, que permitían establecer los meses del año.

Así como hay referencias a columnas grandes o imponentes, se describen también estructuras que parecen ser bastante más sencillas, como las que menciona Cieza de León (1973 [1550]: 214) en el cerro de Carmenga, "de donde salen a trechos ciertas torrecillas pequeñas, que servían para tener en cuenta con el movimiento del sol, de que ellos tanto se preciaron".

Algunas versiones hablan de cuatro grandes columnas, incluso de ocho, y otras de pares de columnas. Se distinguen columnas que permitían anunciar la llegada de solsticios y equinoccios, pero también otras que indicaban cada uno de los meses del año. Según los estudios realizados por Zuidema y Aveni (en Urton 1981: 6), el número y ubicación de los pilares obedecía a diferentes métodos de observación solar y celeste, según los requerimientos. Zuidema (1989: 409) señala que habría habido varias columnas del tipo gnomon en el Cuzco, y distingue al menos dos técnicas complementarias de lectura o medición. Una consistía en medir la sombra que producía el instrumento con respecto al sol y una segunda en observar las salidas y puestas del sol u otros astros en el horizonte, utilizando las columnas como referente a distancia.

Es posible, al menos respecto a la primera técnica descrita, que las columnas fueran la base sobre la que se ponía, cuando así se requería, el gnomon. Como se ha señalado, el gnomon era un instrumento simple, cuya característica era la de ser un elemento alargado o "enhiesto", incluso un "palo" o "bolo" que se colocaba verticalmente sobre una base (Zuidema 1989: 407-412). Según Zecenarro, los gnómones parecen haber sido una variante pequeña de las grandes estructuras cónicas o 
troncopiramidales andinas y que se ubicaban verticalmente sobre superficies niveladas. Señala que podían presentar formas cónicas o de paralelepípedos (es decir, de ángulos rectos), los que son frecuentes en la arquitectura arqueológica incaica de santuarios y huacas (Zuidema 1989: 412, nota 3; Zecenarro 2001: 180).

Con respecto al ushnu, Zuidema sostiene, como se dijo, que el gnomon pudo haber sido una piedra movible, puesta sobre esa estructura solo en los momentos en que cumplía su función astronómica, ya fuera cuando el sol pasaba por el meridiano en general, o cuando este o la luna pasaban por el cenit (Zuidema 1989: 419).

No es nuestra intención describir y discutir aquí las posibles técnicas de lectura celeste que pudieron implementarse en el Cuzco, sino destacar algunos antecedentes relevantes. Según la versión de Betanzos (1987 [1551]: 74), las columnas que había ordenado poner Inca Yupanqui consistían en "cuatro pirámides mármoles de cantería". Las dos de en medio eran de menor altura que las de los lados (que habrían tenido el doble de la estatura de un hombre), "cuadradas" y apartada una de otra por escasos metros. Al parecer, su descripción, sobre todo en lo relativo a la posición y la extensión del espacio que separaba a una columna de otra, responde a una observación efectuada desde la distancia. Garcilaso de la Vega (1995 [1609]: 119-120), que dice haber visto algunas de estas columnas, señala que se trataba de "ocho torres que labraron al oriente y otras ocho al poniente de la ciudad del Cozco, puestas de cuatro en cuatro, dos pequeñas en medio de otras dos grandes". Respecto a las pequeñas, dice que se ubicaban a una distancia de 18 o 20 pies (aproximadamente 10 pasos) una de otra, pero no explicita la distancia que separaba a las mayores (Garcilaso de la Vega 1995 [1609]: 119).

Por su parte, la descripción del cronista Anónimo -en cuyas exhaustivas referencias se basan los estudios de Zuidema y Urton (1976) y Zuidema (2010) - señala una distribución mayor aún de las columnas en el espacio, describiendo una cierta proporcionalidad relativa de las distancias que separan a una columna de otra. Al poniente, en una alta serranía, "hicieron cuatro pilares a manera de torrecillas", que se podían observar de a dos o tres leguas de distancia, abarcando doscientos pasos entre ambos extremos y "50 pasos" entre las dos del medio (Anónimo 1906 [1570-1584]: 151). ${ }^{4}$ Según el autor, "entrando el sol por el primer pilar, se apercebían para las sementeras generales, y començaban a sembrar legumbres por los altos, por ser más tardíos"; al entrar por los dos pilares de en medio, era el momento de sembrar en el Cuzco, siempre en torno al mes de agosto (Anónimo [1570-1584] 1906: 151).

Como señala Zuidema, el sistema de lectura y medición a distancia requería situarse en un determinado punto alineado, desde el centro del Cuzco, con los pilares de la periferia del valle. En base a esta misma crónica, sostiene que ese punto central estaba en los ushnus de ambas plazas públicas del Cuzco (Haucaypata). Como decía el cronista Anónimo (1906 [1570-1584]: 151) "es ansí, que, para tomar el punto del sol, entre los dos pilares de en medio [en el horizonte] tenían otro pilar en medio de la plaça, pilar de piedra muy labrada, de un estado de alto, en un paraje señalado al propósito, que le nombran Osno, y desde allí tomavan el punto del Sol en medio de los dos pilares".

\section{Pilares, sucancas y saywas. Una breve discusión desde el Cuzco}

Hasta el momento, no ha habido acuerdo entre los estudiosos del calendario y la astronomía inka respecto a la cantidad, ubicación, orientación y técnicas de lectura y medición que se aplicaban a las columnas astronómicas del Cuzco. La terminología asociada está también en discusión. La palabra sucanca, por ejemplo, ha sido interpretada de diferentes formas. Según Williams (2001: 124), sucanca era una agrupación de marcadores, torres o "torrecillas" que señalaba fechas significativas del calendario mediante la observación desde puntos prefijados, obedeciendo a una "astronomía de horizonte". Habrían existido dos observatorios formados por sucancas, ubicados al este y al oeste del Cuzco, que marcaban la salida y puesta del sol respectivamente. Hacia el poniente, por ejemplo, se ubicaban cuatro sucancas formadas por cuatro torres cada una, emplazadas en las cumbres de diferentes cerros.

Zuidema, por su parte, considera que sucanca era un referente de medición solar que podía consistir en un lugar en el que se ubicaban torres o columnas, pero también podía tratarse de un sitio o accidente natural de la geografía del entorno del Cuzco (por ejemplo, una montaña). Para este autor, sucanca no era el nombre de los pilares astronómicos, y reconoce muy escasos lugares en los cuales estas torres estaban realmente cumpliendo esa función. Por otra parte, señala que las saywas de los ceques del Cuzco consistían en pilares o "mojones" cuya función era calendárica, pero no astronómica. ${ }^{5}$ Es decir, 
"permitían llevar la cuenta del calendario" (¿a la manera de un quipu?), pero no necesariamente estaban alineadas con algún astro (Zuidema 2010: 121). Esto significa que las saywas eran huacas del sistema de ceques que a veces establecían los puntos de límite de estas líneas rituales en el espacio, y que eran objeto de ofrendas y ceremonias en fechas fijas del año de acuerdo a la organización del calendario cuzqueño. Esto último habría sido lo que les confería su rol de huacas calendáricas, pero no de uso astronómico (Zuidema 2010: 115-122).

\section{LAS SAYWAS ASTRONÓMICAS DEL DESIERTO DE ATACAMA. LOS CASOS DE LASANA Y TOCOMAR}

Desde hace décadas, el registro arqueológico de los caminos incaicos de la antigua Región de Atacama (hoy Región de Antofagasta, Chile) ha mencionado la presencia de estructuras de piedra asociadas al camino, reconocidas como "hitos", "mojones" o "topus"(Núñez 1981; Niemeyer \& Rivera 1983; Hyslop 1992; Lynch \& Núñez 1994; Lynch 1995-1996; Berenguer et al. 2005). Se trata de columnas de piedra cuya construcción manifiesta una previa planificación (a diferencia, por ejemplo, de la apacheta), y que presentan una base aproximada de $1 \mathrm{~m}^{2}$, con alturas (en el caso de que se encuentren mejor conservadas) que pueden alcanzar $1,20 \mathrm{~m}$. Frecuentemente se encuentran en parejas, entre las cuales y equidistante pasa el camino. En otros casos, se trata de una hilera de cuatro o más hitos alineados en forma transversal a la vía. Los investigadores concluyeron inicialmente que estaban destinados a servir como guía o señalización de la ruta, en caso de que el camino se borrara (Hyslop 1992: 61, 174). Sin embargo, estos dispositivos viales representan lo que podría ser una nomenclatura bastante más compleja, asociada no solo a la medición de espacio, sino también de tiempo.

A pesar de que, en el caso del Cuzco, se ha planteado la tesis de que los pilares o "mojones" denominados saywas no fueran astronómicos, consideramos que en el caso del Qhapaq Nan del desierto de Atacama, las evidencias etnohistóricas y astronómicas estarían arrojando una conclusión diferente.

Polo de Ondegardo denomina "saybas" a las columnas astronómicas del Cuzco, señalando que, por ejemplo, la celebración del equinoccio de marzo se establecía a través de la observación del recorrido del sol "por aquellos pilares o topos que llamauan ellos saybas, que están en torno a la ciudad del Cuzco" (en Zuidema 2010: 174). A su vez, en el vocabulario quechua más temprano que se conoce, el término sayhua aparece también asociado a la medición de la posición del sol en el cielo. En efecto, de acuerdo al vocabulario del dominico Fray Domingo de Santo Tomás (1951 [1560]), primer misionero en elaborar una gramática quechua, saywa era sinónimo de ticnu, término utilizado también en relación a deslindes o marcadores de superficies y distancias:

Sayua o ticno. Mojón o lindero de heredad.

Mojonar heredad. Ticnoni o sayuani.

Mojonar camino. Lo mismo (Santo Tomás 1951 [1560]).

Aunque con posterioridad a la edición de ese diccionario, ya no volvemos a encontrar esta asociación entre ambos términos, hacia 1608, el vocabulario de González Holguín (1952 [1608]: 341) entrega una definición de ticnu que lo vincula a la idea de gnomon y de cenit:

Ticnun, o sayani. Estar de pie, o enhiesto o pararse.

Ticnu. El zenit o punto de la mitad del cielo.

Intim ticnurayan. El sol está en el zenit.

Intim ticnuy cumun. El sol passa de mediodía o abaxa. ${ }^{6}$

Si en algún momento se entendió este vocablo como afín al de saywa, podemos concluir que ambos asociaron técnicas de deslinde y marcación de tierras y caminos con la medición del movimiento solar y específicamente con la idea de cenit. El concepto de cenit tenía gran importancia en la cultura y conocimientos astronómicos andinos. En aymara, Bertonio (1984 [1612]) lo denomina sunaque y lo define como "Zenith, o punto del cielo que corresponde a nuestra cabeça", como "estar el sol en mediodía", o estar el sol o la luna "sobre la cabeza". Lo asocia además con la "cumbre del cerro", la "cumbre de la casa" o la "coronilla de la cabeza". Ticnu en quechua y sunaque en aymara nos remiten a un sistema de medición del tiempo donde el gnomon (el cerro, la casa u otro hito) es el referente (Zuidema \& Urton 1976).

Otra razón que nos llevó a sospechar una posible alineación astronómica de las saywas es que estas, aunque dispuestas en forma transversal al camino, no eran exactamente perpendiculares a aquel. Más bien dibujaban una diagonal en sentido este-oeste, lo que nos advirtió que su función no era indicar la orientación del camino en caso de que este de borrara. Pero, en este caso, ¿a qué estaban apuntando? 


\section{Las saywas de Lasana}

Este sitio se encuentra en el valle superior del río Loa (correspondiente a la Región de Antofagasta, Chile) y se ubica en lo que fue el noreste de la antigua provincia colonial de Atacama. Esta zona corresponde a un corredor que articula rutas provenientes de los oasis más bajos del curso del río como también de la cuenca del salar de Atacama. Hacia el norte, el camino continúa en dirección a los valles y altiplano de Tarapacá como también hacia el altiplano meridional de Bolivia. El tramo de camino incaico a que nos referimos va bordeando la profunda quebrada del río Loa y, especialmente, desde la localidad de Lasana hacia el norte, está trazado en plena pampa desértica por la ladera oeste del cañón, en forma más o menos paralela al curso del río (Berenguer et al. 2005) (fig. 2). Unos $14 \mathrm{~km}$ al norte de Lasana, se encuentra una serie de hitos de piedra, muy bien construidos y dispuestos en línea recta, que atraviesan el camino. Se trata de un alineamiento de estructuras de base cuadrada que dibuja una línea transversal aunque inclinada, en una orientación aproximada este-oeste y en plena pampa. Los dos hitos centrales, ubicados en ambos costados de la vía, están separados entre sí por unos $8 \mathrm{~m}$ y alcanzan una altura de 1,20 m. La hilera o línea está compuesta por las dos columnas centrales, una tercera columna ubicada a unos $200 \mathrm{~m}$ hacia el este, una cuarta a otros $300 \mathrm{~m}$ de distancia en la misma dirección y una quinta saywa, semi destruida, ubicada a una distancia superior a los $400 \mathrm{~m}$ (fig. 3).?

Coincidimos con Berenguer (2007), quien interpretó este alineamiento como un deslinde provincial vinculado principalmente a la actividad minera inkaica en la región. Por tratarse de un sitio amojonado por el Inca que abarca una extensión que no hemos vuelto a encontrar en nuestras investigaciones posteriores, creemos que se trata de un sitio de especial jerarquía (fig. 4). Si bien en el presente registro solo presentamos y evaluamos cinco columnas (las dos centrales y tres hacia el este), resulta muy posible -desde el punto de vista de la simetría que caracteriza a la arquitectura imperial- que originalmente se haya tratado de unas ocho columnas (fig. 5). En efecto, además de las mencionadas, pudo haber habido otras tres columnas hacia el oeste que habrían sido destruidas con la construcción de la carretera aledaña. Estas hipótesis deberán ser corroboradas en las siguientes etapas de investigación del sitio.

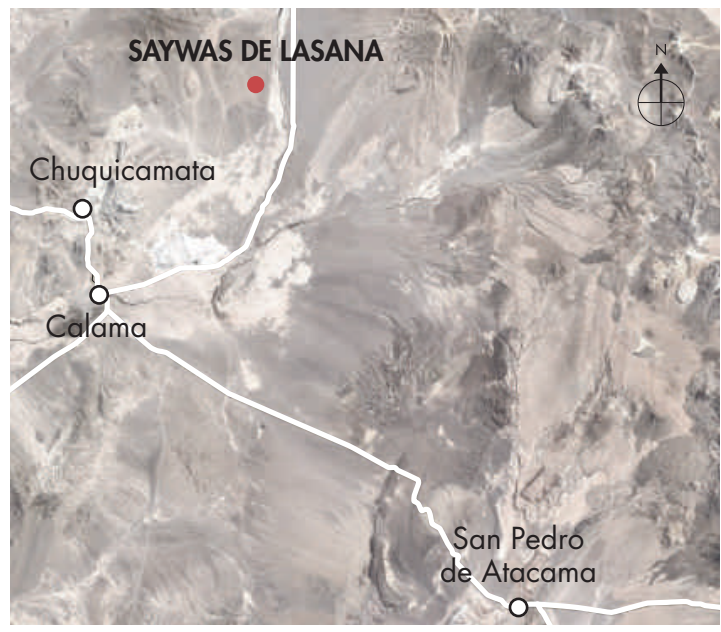

Figura 2. Mapa con la ubicación aproximada de las saywas de Lasana. Figure 2. Map with the approximate location of the Lasana saywas.

\section{Deslindes, líneas y ceques}

El sistema de ceques del valle del Cuzco, establecido con fines religiosos, calendáricos, sociales y políticos, estaba compuesto por una serie de huacas dispuestas en virtuales líneas rectas irradiadas desde el centro urbano hasta perderse en el horizonte. Según Urton (1984: 15, 56), los ceques pueden ser entendidos como "líneas demarcatorias" que deslindaban el espacio ritual correspondiente a diferentes grupos políticos y sociales, regulando, por una parte, la interacción y confrontación entre ayllus y panacas, y por otra, estableciendo un ordenamiento espacial-territorial del valle de Cuzco.

Efectivamente, es significativo que los vocabularios de los siglos XVI y XVII asocien semánticamente el concepto incaico de ceque, como línea divisoria, con la práctica institucionalizada de "amojonar", "medir" y "repartir":

\footnotetext{
Sayhuani, sayhuacuni: amojonar tierras, hacer linderos. Sayuac o cequec: deslindador.

Cequeni o sayuani: deslindar heredad o diuidirla con lindero. Ceqque: raya, línea, término.

Ceqqueni: rayar, linear, deslindar.

Allpa: La tierra de labor y el suelo.

Allpa tupuk apu, o cequek apu: medidor o repartidor de tierras (Santo Tomás 1951 [1560]; González Holguín1952 [1608]).
}

La tarea de los ceques apu correspondería a la ilustración de Guamán Poma en la que representa a estos "jueces" (el "mojonador" y el "medidor") llevando a cabo su tarea 


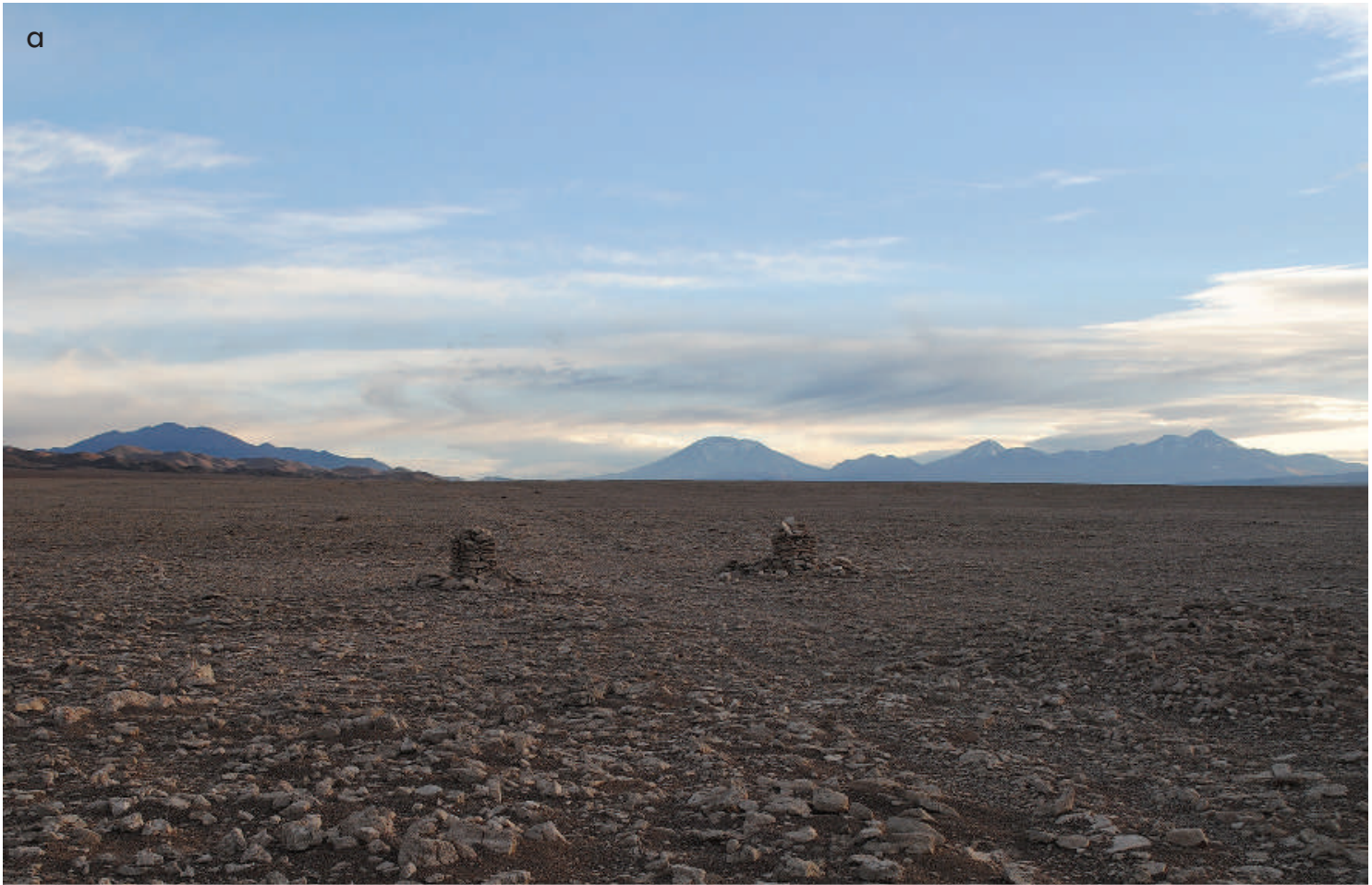

b

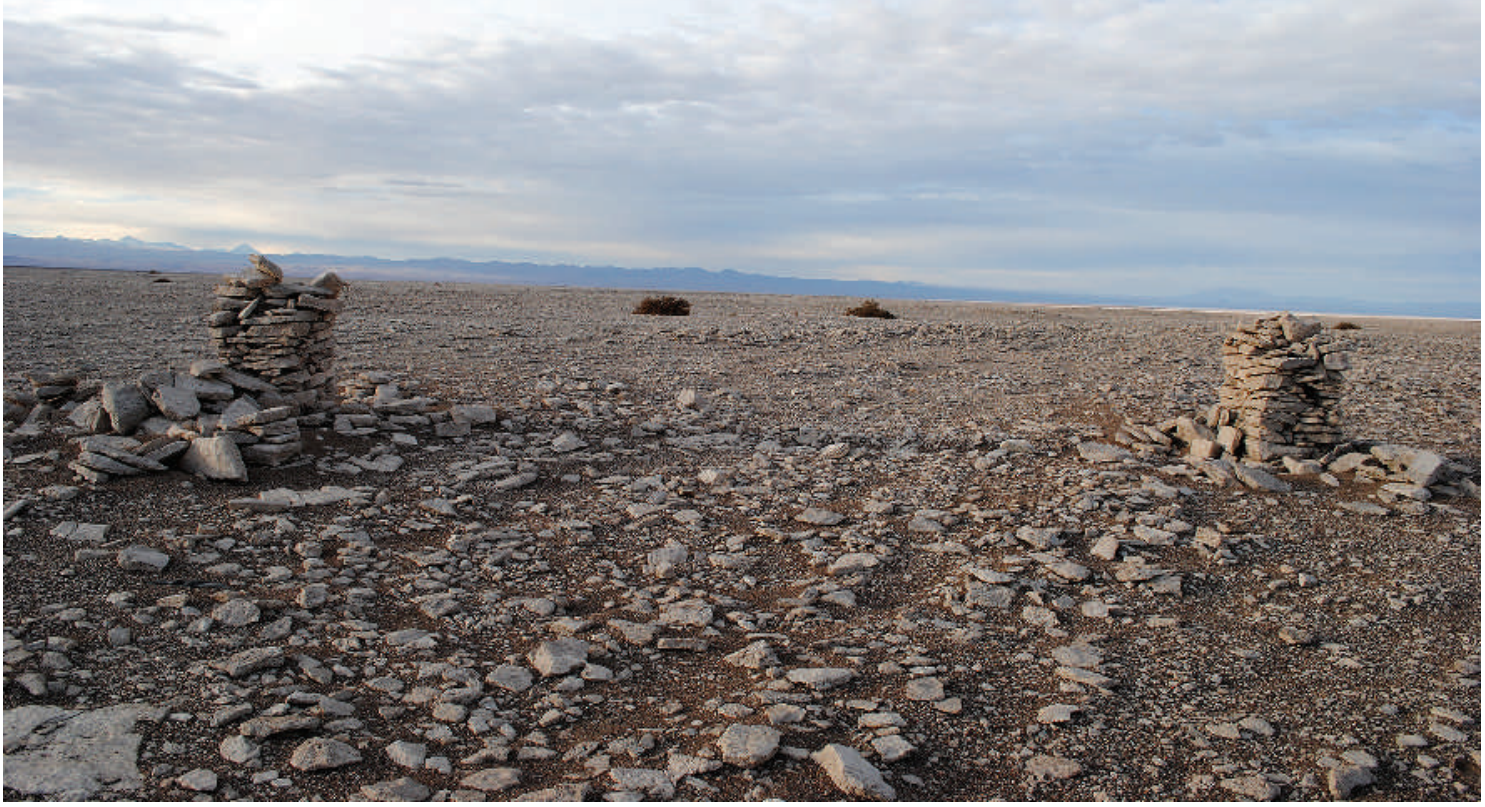

Figura 3 a y b. Las dos columnas centrales de Lasana. Entre ambas pasa el Camino del Inka (fotografías de W. Faúndez). Figure 3 a and b. The two central columns of Lasana. The Inka Road runs in between them (photos by W. Faúndez). 


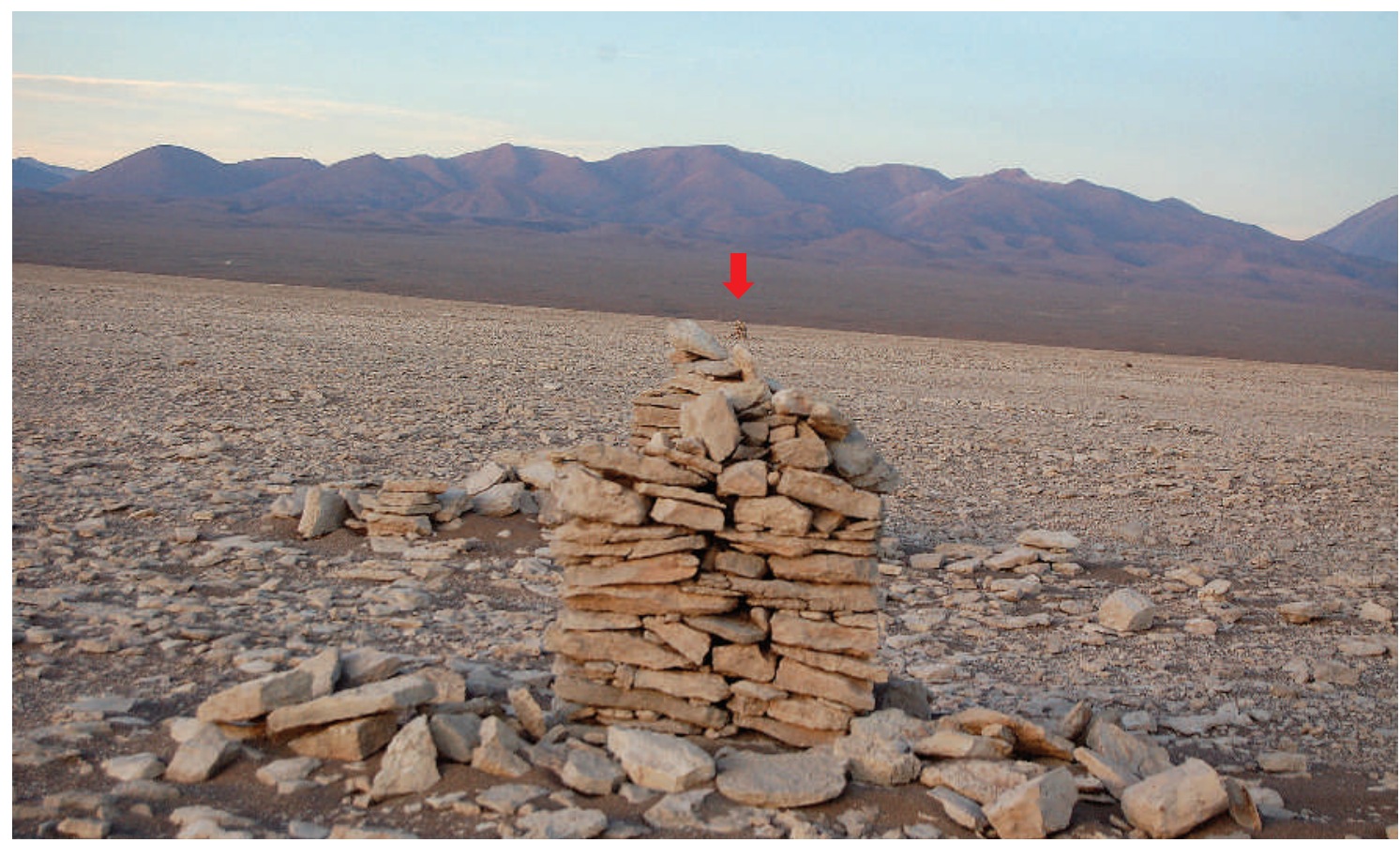

Figura 4. Las sayhuas centrales de Lasana en línea. Al fondo, hacia el este, la flecha indica la tercera columna (fotografía de C. Vitry). Figure 4. The main sayhuas of Lasana in line. In the background, towards the east, the arrow indicates the third column (photo by C. Vitry).

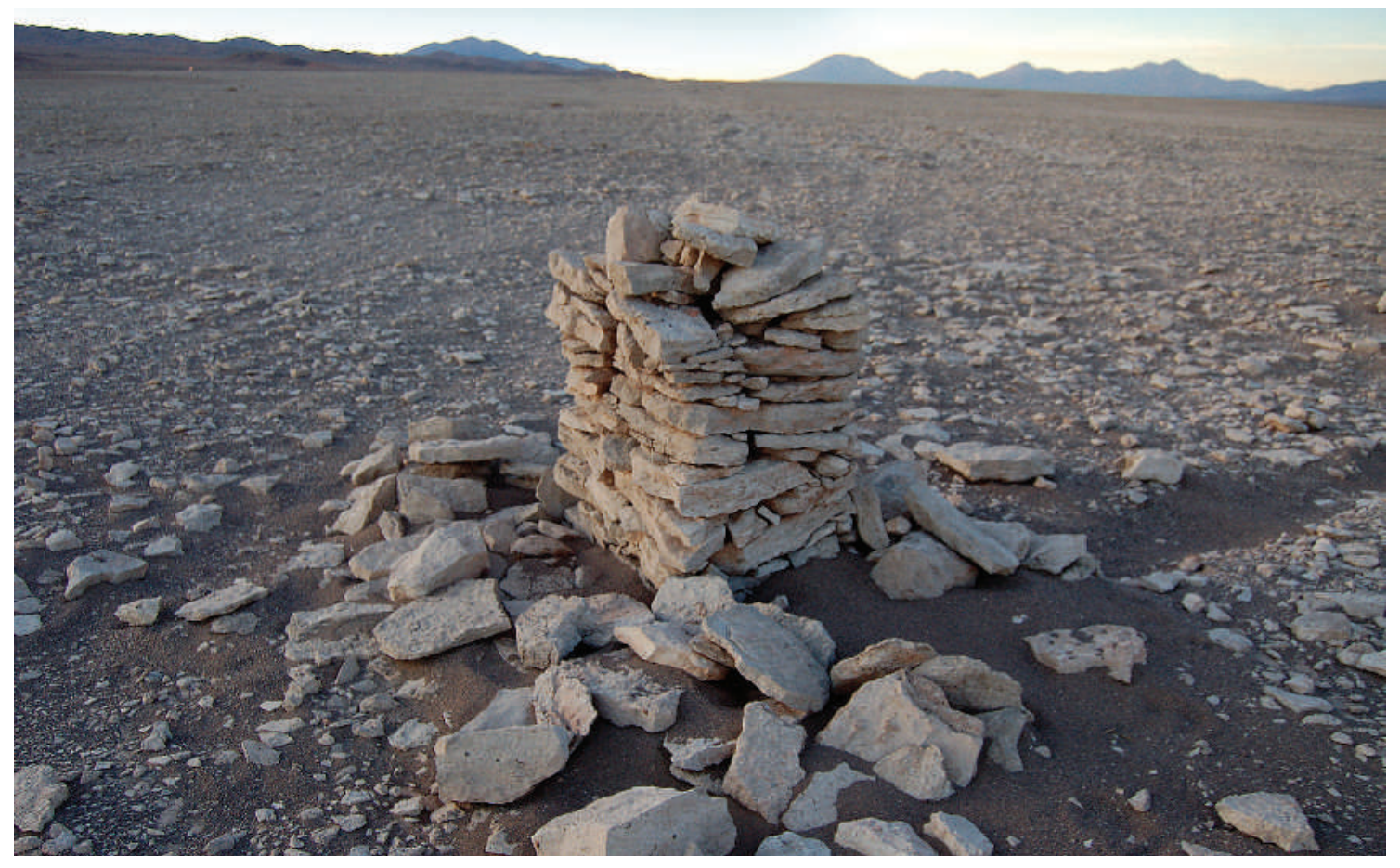

Figura 5. Saywa central del borde oeste del camino de Lasana (fotografía de C. Sanhueza). Figure 5. Central Saywa on the western edge of the Lasana road (photo by C. Sanhueza). 
de deslindar territorios o jurisdicciones. Según Guamán Poma, los amojonadores del Inca, recibían el nombre de Sayhua checta suyoyoc (fig. 6). El significado de la expresión se relaciona con "lindero" o "mojón" ("saywa"); con "partir" o "dividir" ("cheqta"); y con aquel que administra una provincia o una subdivisión (suyuyuq) (González Holguín 1952 [1608]). Estas subdivisiones o distritos se establecían principalmente en relación a las actividades productivas, por lo que la construcción del Qhapaq Ñan del Loa habría tenido como principal objetivo unir y articular una ruta de acceso y de circulación de recursos mineros de la región. El territorio deslindado por el Inka marcaría, posiblemente, una de las fronteras internas de Atacama, que a modo de ínsulas o provincias territorialmente discontinuas, el Estado iba amojonando durante su expansión (Berenguer 2007).

Otra ilustración de gran interés al respecto es la representación de las saywas del Inka del manuscrito de Martín de Murúa (2004 [1590]), en la que se pueden observar, justamente, líneas de saywas tipo ceques organizando el territorio andino (figs. 7 y 8 ).

\section{Las saywas y el sol}

El avance de la investigación hizo indispensable el apoyo científico de los astrónomos Juan Cortés López del observatorio internacional Joint ALMA ObservatoryNational Radio Astronomical Observatory (NRAO) y Sergio Martín Ruiz del European Southern Observatory (ESO). Con ese objeto, se elaboró una ficha específica del sitio, incorporando la información básica requerida (UTM, azimut, altitud, etc.). Se determinó el año 1500 DC como una fecha aproximada y estandarizada para realizar simulaciones con programas especializados de astronomía respecto a las salidas y puestas de sol, escogiendo como principales fechas de referencia los días de solsticios y equinoccios.

El resultado en el caso de Lasana -con un azimut de $64^{\circ}$ - fue concluyente. El informe astronómico reveló que la ubicación de las columnas al año 1500 correspondía a la salida del sol en el solsticio de invierno, tal como se pudo fotografiar con posterioridad. En efecto, la línea de saywas está orientada hacia el punto de salida del sol en torno al 21 de junio, como lo muestran las figuras 9 y 10. Este alineamiento, que en su estado actual alcanza una longitud aproximada de $1 \mathrm{~km}$ y que bien pudo haber abarcado el doble de extensión en sus orígenes, se orienta con el punto de salida del sol en una

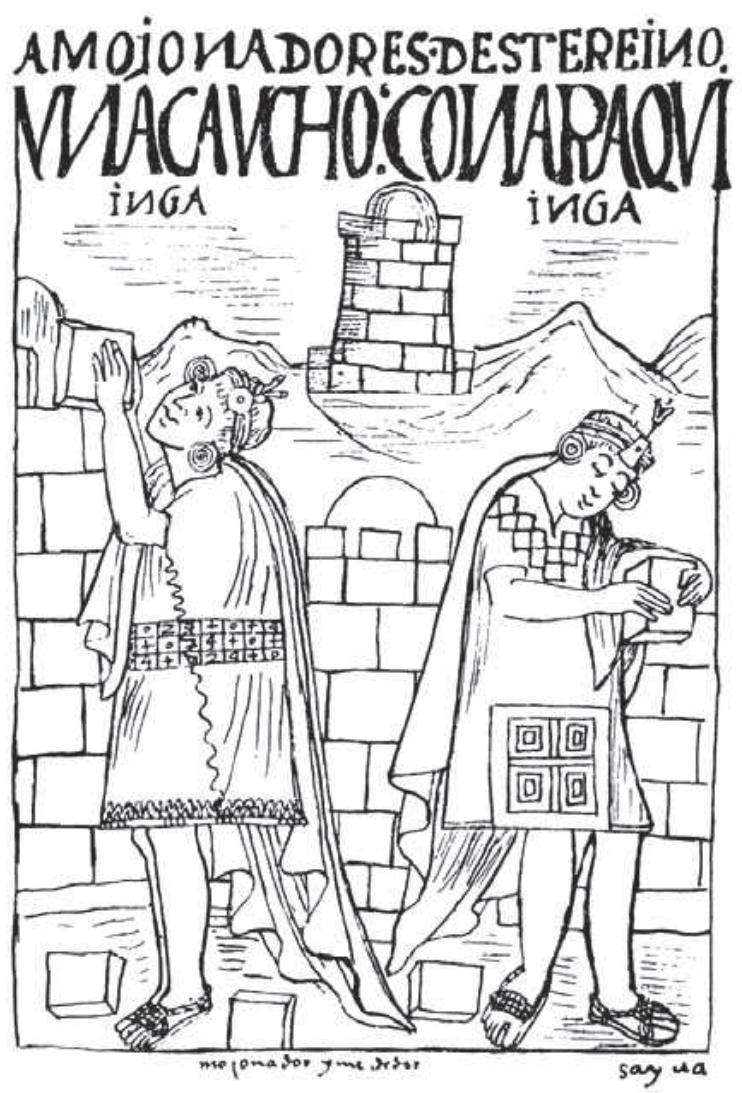

Figura 6. El "amojonador" y "medidor" del Inka, ejerciendo la política estatal de amojonamiento y medición de tierras, recursos y provincias. Figure 6. The "amojonador" ('land marker') and "medidor" ('land measurer') of the Inka, implementing the state policy of marking and measuring land, resources and provinces.

fecha muy relevante. Durante unos días Inti se detiene, sentado en su "silla", para luego recomenzar su caminata en sentido contrario para alcanzar el 21 de diciembre su otra silla en el sur.

\section{Las saywas de Tocomar}

La ruta que los españoles llamaron "del Gran Despoblado", se iniciaba en el borde sur del salar de Atacama, atravesaba longitudinalmente la región más árida del desierto y se extendía por unos $500 \mathrm{~km}$ hasta las cercanías del valle de Copiapó. Aunque ha sido una ruta utilizada desde tiempos muy anteriores a los inkas (Lynch \& Núñez 1994), el camino del despoblado se distingue de otras huellas producidas por el uso de personas o animales, por su trazado muy recto. Se trata de una huella despejada cuyo ancho puede abarcar, sobre todo en aquellos sectores menos alterados por el uso posterior, unos tres 


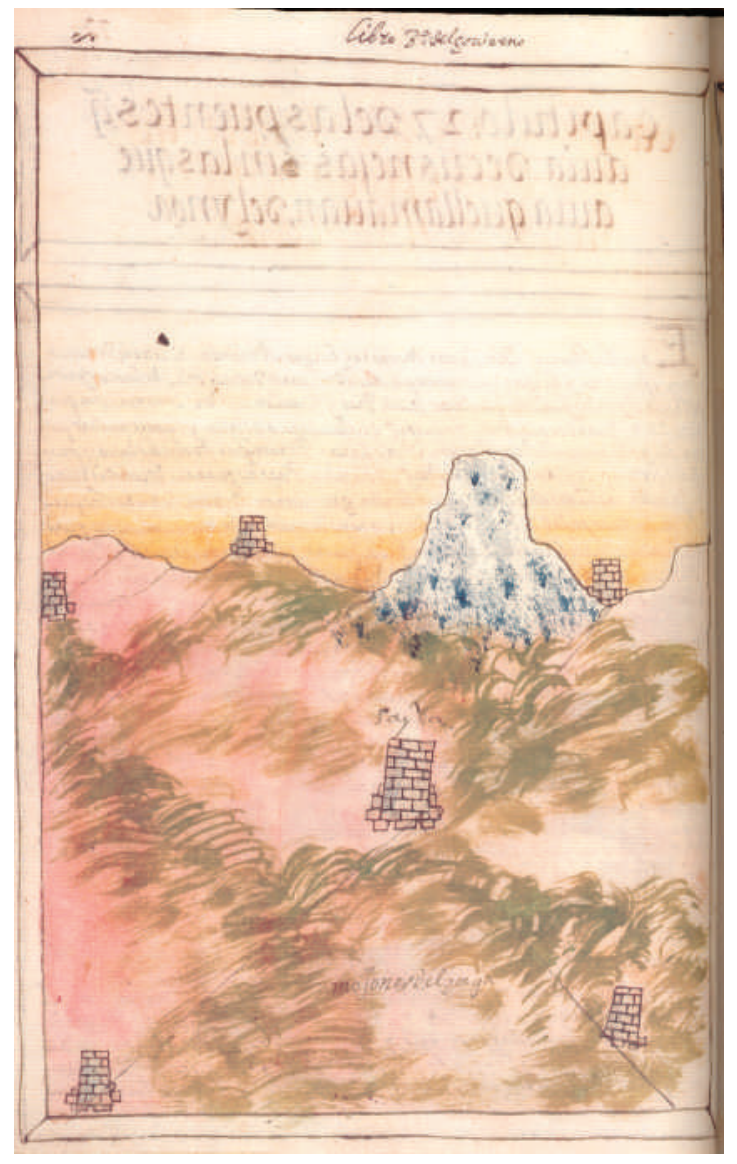

metros, y en otros puede reducirse a una pequeña huella de entre 30 y 60 cm (Iribarren \& Bergholz 1972-1973: 241-242; Lynch 1995-1996; González 2007).

Los estudios arqueológicos han coincidido en que el Camino Inka del despoblado fue una vía expedita destinada a las comunicaciones administrativas dentro del Tawantinsuyu (especialmente desde y hacia las "provincias" de Chile) y apta solo para el tránsito de grupos pequeños por su limitada provisión de agua. También habría sido una vía de circulación de bienes y recursos, sobre todo mineros, incluso de minerales provenientes de los valles centrales de Chile (Niemeyer \& Rivera 1983: 254-157). Pero, además, esta ruta conectaba una serie de sitios sagrados, especialmente santuarios de altura como el importante complejo ceremonial del volcán Llullaillaco (Niemeyer \& Rivera 1983; Lynch 1995-1996; Vitry 2008).

Las saywas de Tocomar se ubican en una extensa pampa a orillas del borde sur del salar de Punta Negra

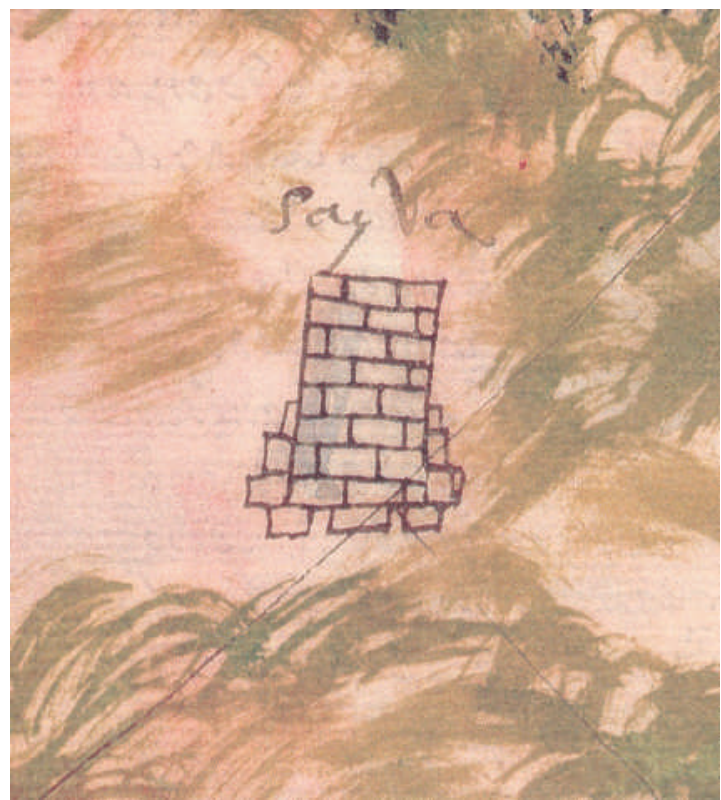

Figura 8. Detalle de una saywa del Inka. Figure 8. Detail of an Inka saywa.

4 Figura 7. Las "sayvas" o "mojones del ynga", en la ilustración de Murúa (2004 [1590]: 163). Nótese cómo están dispuestas en líneas rectas. Figure 7. The "sayvas" or "mojones de ynga", in an illustration by Murúa (2004 [1615]: 163). Note how they are positioned in straight line.

(fig. 11). Llegamos a ellas gracias a una fotografía publicada por Lynch (1995-1996) que llamó poderosamente nuestra atención, puesto que las columnas (casi completamente destruidas) estaban unidas por una hilera de piedras (fig. 12). ${ }^{8}$ Como se puede observar en la foto del sitio, la columna correspondiente al lado este había sido prácticamente arrasada en uno de sus costados por maquinaria pesada, tal vez durante la construcción de un camino aledaño. A pesar de ello, es posible proponer que el trazado de esta línea de referencia corresponde a una antigua técnica de medición astronómica (fig. 13).

En efecto, Sarmiento de Gamboa (1942 [1572]: 93) describe un complejo sistema de "astrolabios" o "relojes anuales" dispuestos hacia el levante y hacia el poniente del Cuzco, compuestos por columnas de piedra. Señala que para demarcar la posición en la que el sol se desplazaría en ciertas fechas, el Inka había mandado a hacer en el suelo y entre las columnas "ciertas rayas niveladas conforme a las mudanzas del sol”. Esta técnica tenía no 


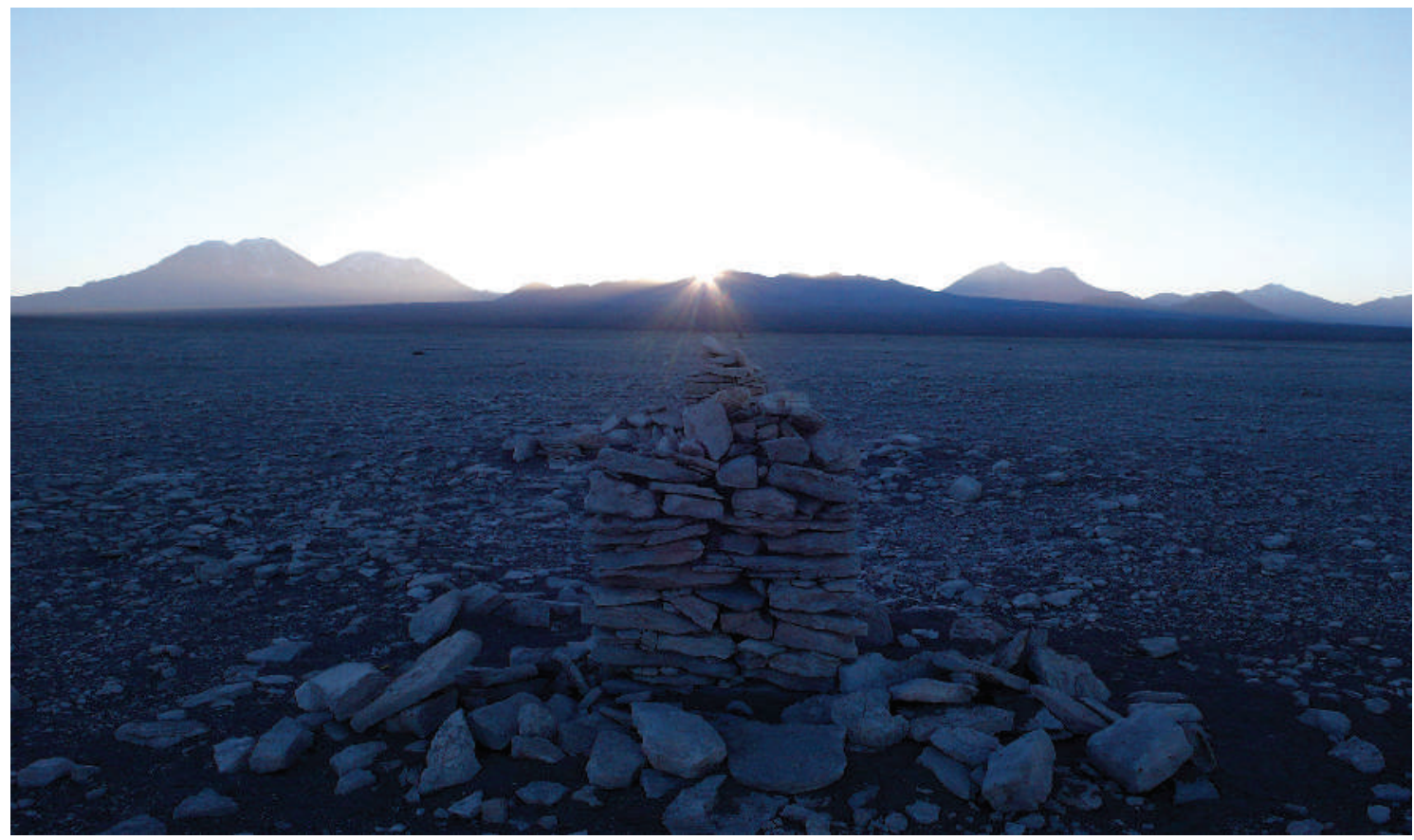

Figura 9. Amanecer del 21 de junio de 2015, marcando el solsticio de invierno en Lasana. La foto está tomada desde las dos saywas centrales en dirección oeste-este (fotografía de Sebastián del Campo). Figure 9. Dawn of June 21, 2015, marking the winter solstice in Lasana. The photo was taken from the two central saywas looking eastward (photo by Sebastián del Campo).

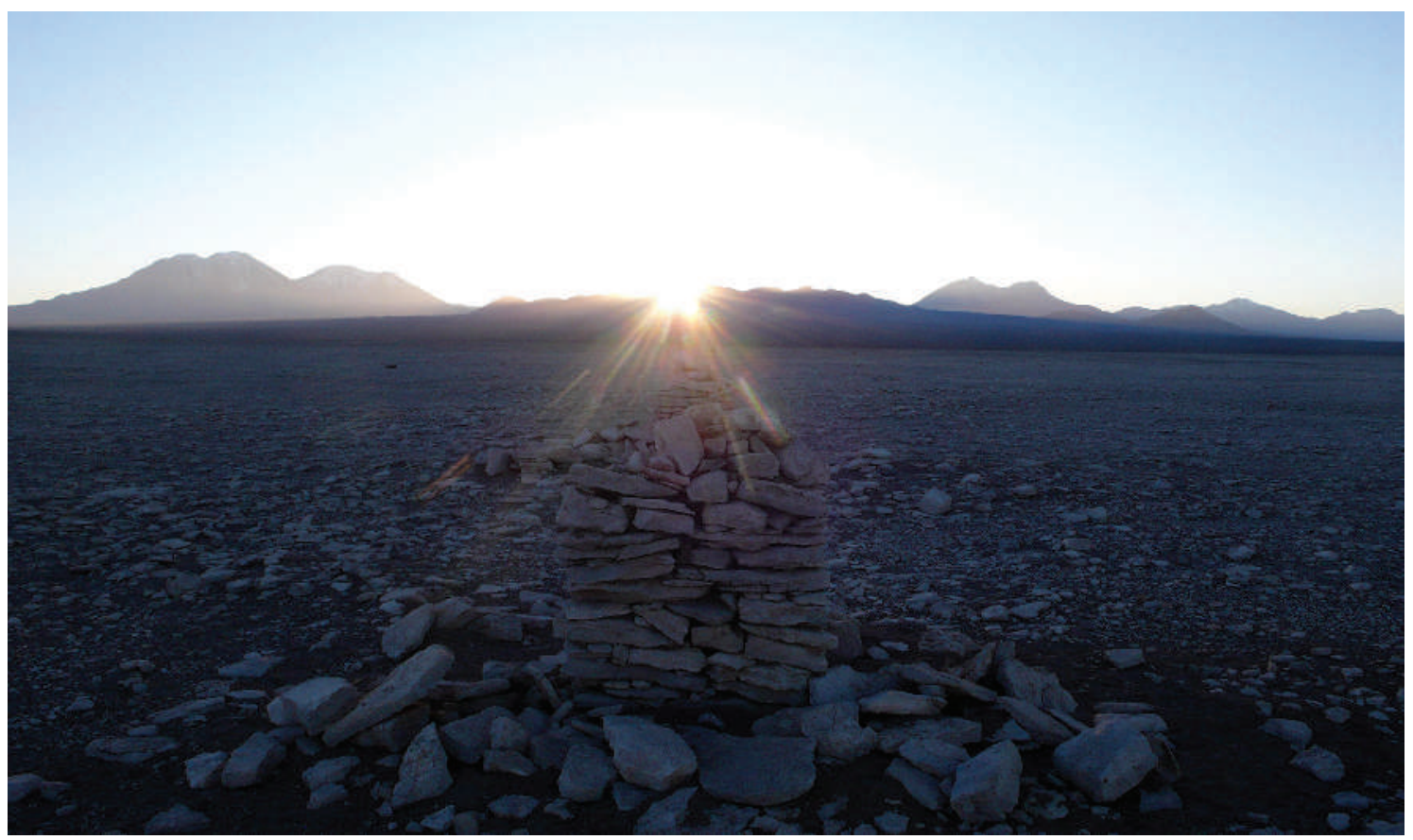

Figura 10. Salida del sol en el solsticio de invierno en Lasana (fotografía de Sebastián del Campo). Figure 10. Winter solstice sunrise in Lasana (photo by Sebastián del Campo). 


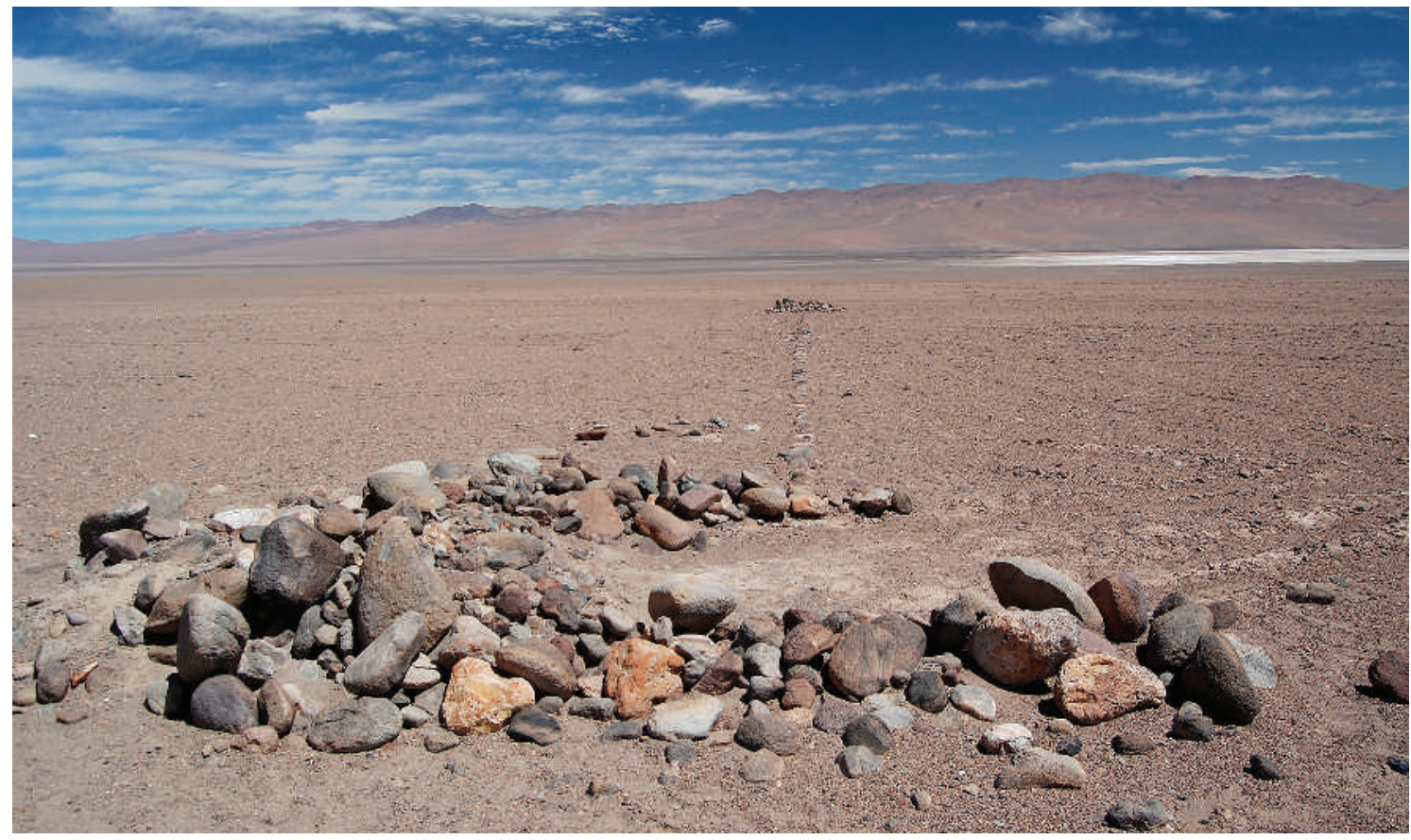

Figura 12. Despoblado de Atacama, saywas destruidas en el camino incaico de Tocomar. Al fondo, al oeste, la cordillera de Domeyko, paralela a los Andes (fotografía de M. Núñez). Figure 12. Saywas in ruins along the Inca Road in Tocomar, Atacama Desert. In the background, to the west, lies the Domeyko mountain range, parallel to the Andes (photo by M. Núñez).

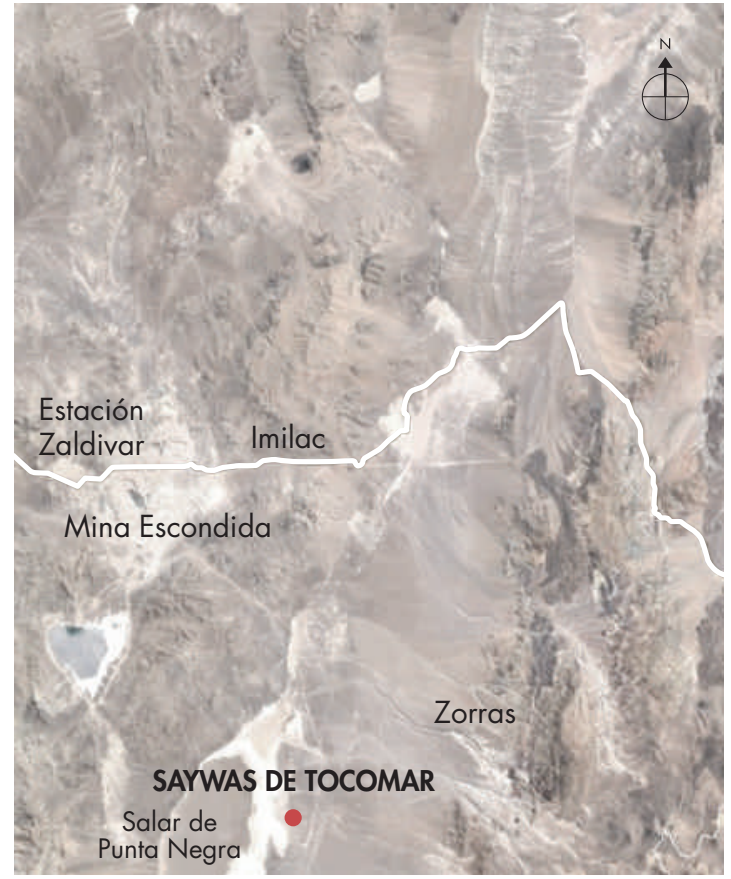

Figura 11. Mapa con la ubicación aproximada de las saywas de Tocomar. Figure 11. Map with the approximate location of the saywas of Tocomar.

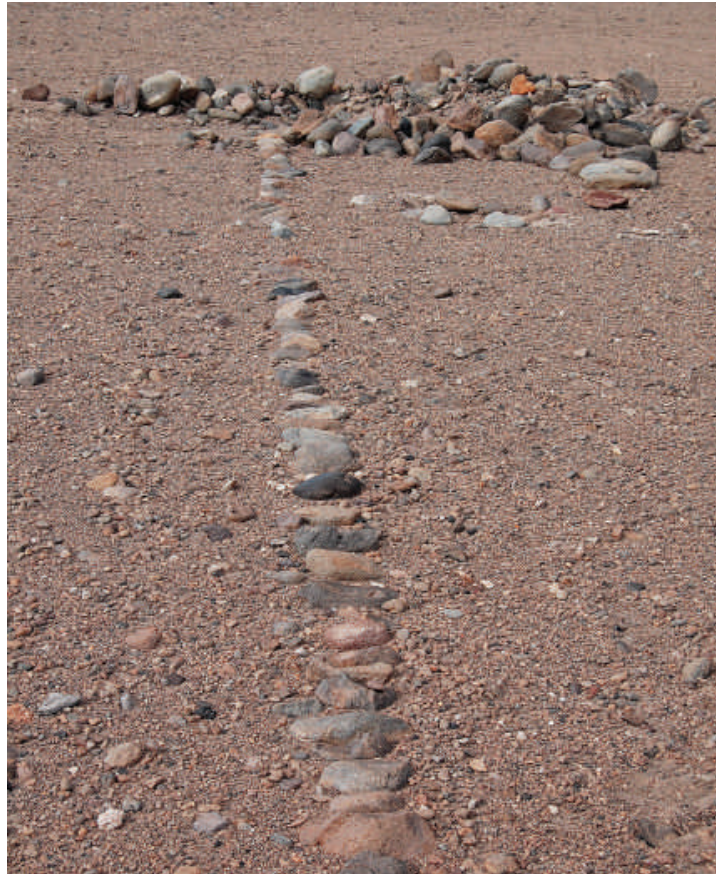

Figura 13. Detalle de la línea de piedras semiincrustadas en la tierra, que unía las columnas de Tocomar. Figure 13. Detail of a stone road partially embedded in the soil, that used to connect the columns of Tocomar. 
solo gran importancia astronómica, sino también ritual y política, como se puede desprender de la descripción de Garcilaso de la Vega (1995 [1609]: 120):

Para verificar el equinoccio tenían columnas de piedra riquísimamente labradas, puestas en los patios o plazas que había ante los templos del sol. Los sacerdotes [...] echaban por hilo, de oriente a poniente, una raya que por larga experiencia sabían donde debían poner un punto y otro. Por la sombra que la columna hacía sobre la raya veían que el equinoccio se iba acercando y cuando la sombra tomaba la raya de medio a medio, desde que salía el sol hasta que se ponía -y que a mediodía bañaba la luz del sol toda la columna en derredor sin hacer sombra aparte alguna-, decían que aquél día era el equinoccial. Entonces, adornaban las columnas con todas las flores y yerbas olorosas que podían haber $y$ ponían sobre ellas la silla del sol y decían que aquel día se asentaba el sol con toda su luz de lleno en lleno sobre aquellas columnas.

En este caso, el cronista parece estar confundiendo el equinoccio con el paso del sol por el meridiano local y el cenit, evento que parece haber sido de gran importancia (Williams 2001: 134). Según Zuidema (1989: 405-406), el paso del sol por el cenit, es decir, aquel momento en que el gnomon no proyectaba sombra, era un acontecimiento ceremonial muy significativo. Sostiene que la referencia de Garcilaso, que hace coincidir el paso solar por el cenit con el día del equinoccio, parece apelar a una situación "ideal" que solo se presenta en las zonas ubicadas sobre la línea ecuatorial. No obstante, la técnica descrita constituía un principio de medición y de predicción fundamental para las fechas importantes del calendario estatal. Como efectivamente agrega Garcilaso, las columnas más apreciadas por los incas, eran aquellas que quedaban más próximas a la línea equinoccial, puesto que en ellas "menos sombra hacía la columna al mediodía”. Así, las columnas que estaban más cercanas a la ciudad de Quito eran las más veneradas "porque decían que aquellas eran asiento más agradable al sol, porque en ellas se asentaba derechamente y en las otras de lado" (Garcilaso de la Vega 1995 [1609]: 121).

¿Pudo la hilera de piedras de las sayhuas de Tocomar estar cumpliendo la función de esas "rayas" como punto de referencia para una observación solar in situ?

Otro hallazgo muy valioso que hicimos en este sitio fueron dos ejemplares de piedra (basalto) que, como mostraremos a continuación, eran dispositivos que se colocaban sobre las saywas y que, de acuerdo a nuestras hipótesis, tenían una función o un significado asociado a la idea de gnomon. Previo a su descripción será necesario aportar algunos antecedentes.

\section{Saywas y gnómones. Una nueva hipótesis de trabajo}

Como es sabido, la principal dificultad para estudiar las columnas del Cuzco y su funcionamiento calendárico y ritual es que estas fueron destruidas por los extirpadores de idolatrías y solo en casos excepcionales se han podido identificar algunas de sus bases o cimientos (Urton 2006). Así también las saywas de los caminos de Atacama

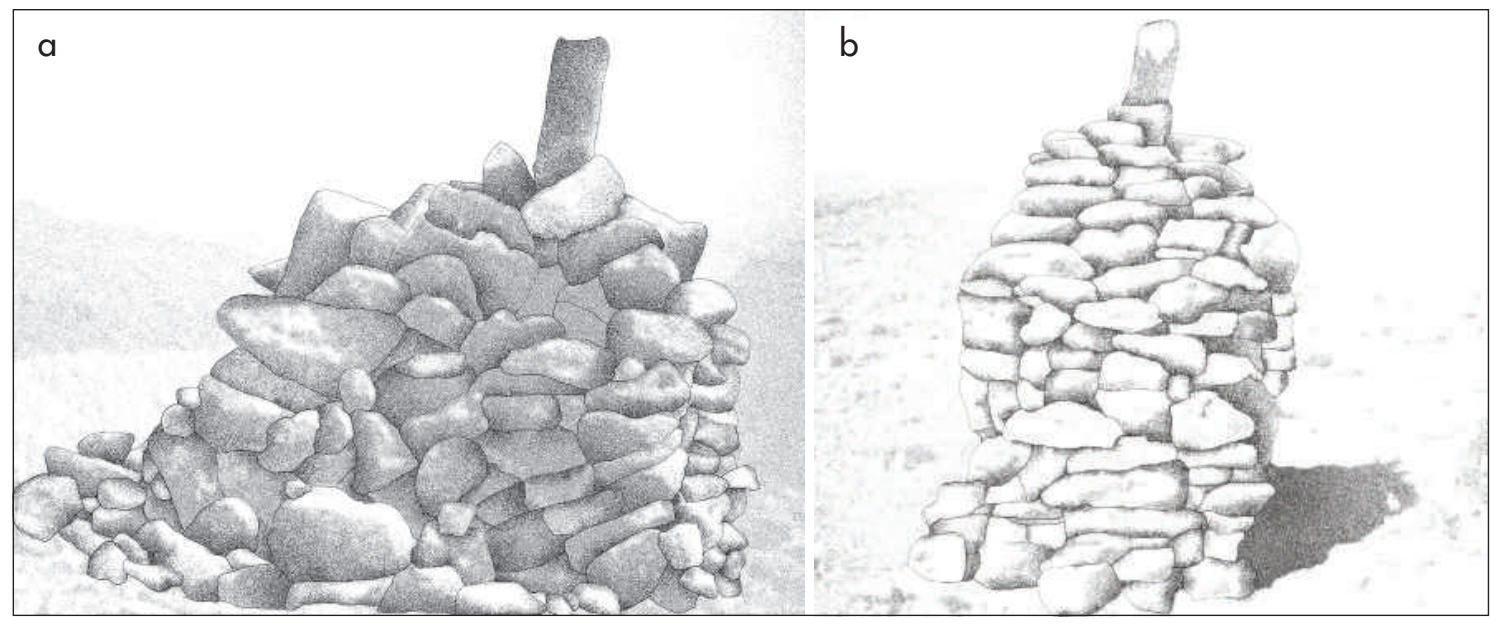

Figura 14: a) Saywa en sector tambo de Catarpe, San Pedro de Atacama; b) Saywa de 2 m de altura (camino inkaico de Río Grande/Río Salado), Atacama (dibujos a partir de Lynch 1995-1996). Figure 14: a) Saywa in the area of Catarpe, San Pedro de Atacama; b) Saywa, 2 high (Inka Road, Río Grande/Río Salado), Atacama (drawings from Lynch 1995-1996). 
frecuentemente han sido desarmadas y son escasas las oportunidades en que se puede observar lo que pudo haber sido su estructura original relativamente completa.

En los casos en que estas se encuentran mejor conservadas, es posible apreciar su parte superior o superficie como una base que tiende a ser plana o lisa. Creemos que esto respondía al propósito de poner un objeto sobre ellas, como lo demuestran algunos hitos o "mojones" ubicados en otros sectores de Atacama. Efectivamente, Lynch (1995-1996: 191) registra algunos hitos de los caminos de Catarpe y Río Grande (en la región de San Pedro de Atacama) -e incluso los compara con otros ejemplos similares de la región de Saxamar, en Bolivia- a los que describe como columnas de piedras cuidadosamente apiladas, que contienen lo que califica como una "oreja" (ear) en su superficie (fig. 14). Las fotos que reproducimos aquí provienen de la publicación citada y manifiestan, precisamente, la presencia de piezas líticas "hincadas" o superpuestas sobre las columnas y cuyas características obedecen a la estructura recta y vertical, así como al tamaño moderado del gnomon.

Como decíamos anteriormente, en los eventos en que el sol pasaba por el equinoccio o por el cenit, según Garcilaso, los incas adornaban las columnas que tenían puestas en un patio o plaza, "y ponían sobre ellas la silla del sol", señalando que ese día "el sol se asentaba con toda su luz", lo que era ocasión de grandes festejos. Estas descripciones son doblemente interesantes puesto que, además de describir una forma de medición y predicción de los movimientos solares, señala la diversidad de estructuras que podían servir de soporte material a la ritualidad solar. En este caso, la silla o asiento del sol, el símbolo del poder de la divinidad celeste y el símbolo del poder político del Inca, no estaba sobre una placeta, sino sobre una columna. Podríamos pensar, siguiendo a Zecenarro (2001: 182), que la metáfora y el símbolo del "asiento" o "tiana" del sol era, al menos en estos casos, justamente el gnomon, es decir, la estructura vertical que se colocaba sobre las columnas y sobre la cual la divinidad se posaba o se "asentaba" en toda su plenitud.

En el Cuzco, solo la elite gobernante podía adorar la representación "oficial" del Sol (Inti). Betanzos, la describe como un "bulto" de oro en forma de niño de un año que se encontraba en el templo principal y a la que solo accedían el Inca y los grandes señores. Pero, a su vez, existía otra imagen para que "el pueblo" pudiera adorar a la divinidad. Para eso, el Inca "hizo poner en medio de la plaza del Cuzco [...] una piedra de la hechura de un pan de azúcar puntiaguda hacia arriba y enforrada en una faja de oro la cual piedra hizo ansi mismo labrar el día que mandó hacer al bulto del sol y esta para que el común adorase" (Betanzos 1987 [1557]: 52). Esta otra imagen venerada por "el común", que consistía en una piedra de la forma de un "pan de azúcar", parece ser una representación muy emparentada con los dispositivos puestos sobre las sayhuas de Atacama. De allí que otro de los hallazgos valiosos que hicimos en el sitio de Tocomar fue el de ambos gnómones, semisepultados bajo las piedras. Ambos artefactos eran de basalto, pero destaca entre ellos el formato y tamaño de la pieza lítica de la columna este que medía $66 \mathrm{~cm}$ de largo, $18 \mathrm{~cm}$ de ancho y $14,5 \mathrm{~cm}$ de grosor. Con cuatro caras bien definidas en relación a los ejes longitudinales, presentaba su extremo proximal (base) pulido. Esta pieza requería de un soporte muy adecuado para su peso (que podríamos calcular en unos $30 \mathrm{k}$ ) y tamaño. Es decir, es posible que la unión entre la pieza y la columna haya requerido de una técnica específica para mantenerla en forma vertical (Wilfredo Faúndez, comunicación personal, 2012) (fig. 15). ${ }^{9} \mathrm{El}$ parecido entre esta pieza de basalto y las de las fotografías expuestas (fig. 14), como también la ilustración de Martín de Murúa que presenta una piedra hincada sobre una torrecilla, nos confirma la sospecha de que se trata del gnomon o dispositivo que la coronaba (fig. 16).

Creemos que la representación de Martín de Murúa nos sitúa en un campo de significados comunes que vinculan esa ilustración con la representación de la divinidad solar y con las saywas o columnas de los Caminos del Inka. En ese sentido, estas piezas, dispuestas sobre cada saywa podían simbolizar el momento donde se "asentaba", en determinadas fechas, la divinidad solar.

Por sí sola, la información etnohistórica presentada hasta aquí nos parece de gran relevancia para continuar investigando. Pero, además, nuevamente el diagnóstico de los astrónomos se inclinó favorablemente al identificar este alineamiento, cuyo azimut alcanzó los $63,73^{\circ}$, con el punto de salida del sol en el solsticio de invierno (Juan Cortés, comunicación personal, 2012).

\section{ALGUNAS PREGUNTAS Y CONCLUSIONES PRELIMINARES}

El hecho de constatar una función astronómica al menos en algunos casos de las saywas del Camino Inka del Desierto de Atacama representa un hallazgo importante. 


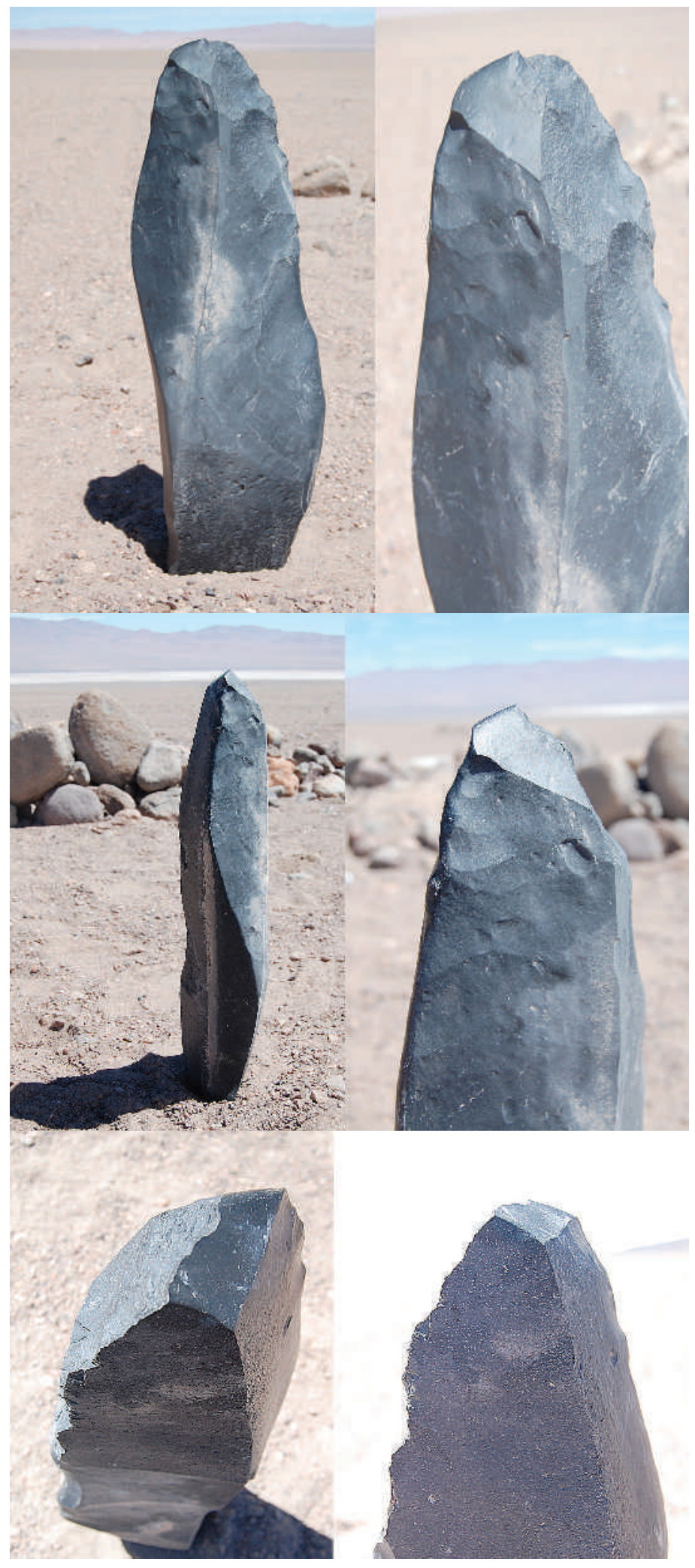

Figura 15. Pieza lítica de la columna este. Su tamaño y forma natural fue especialmente seleccionada para ser esculpida y colocada sobre la columna por donde sale el sol (fotografías de $\mathrm{M}$. Núñez). Figure 15. Lithic piece, eastern column. Its natural size and shape was specially selected for being sculpted and placed upon the column where the sun rises (photographs by M. Núñez). 


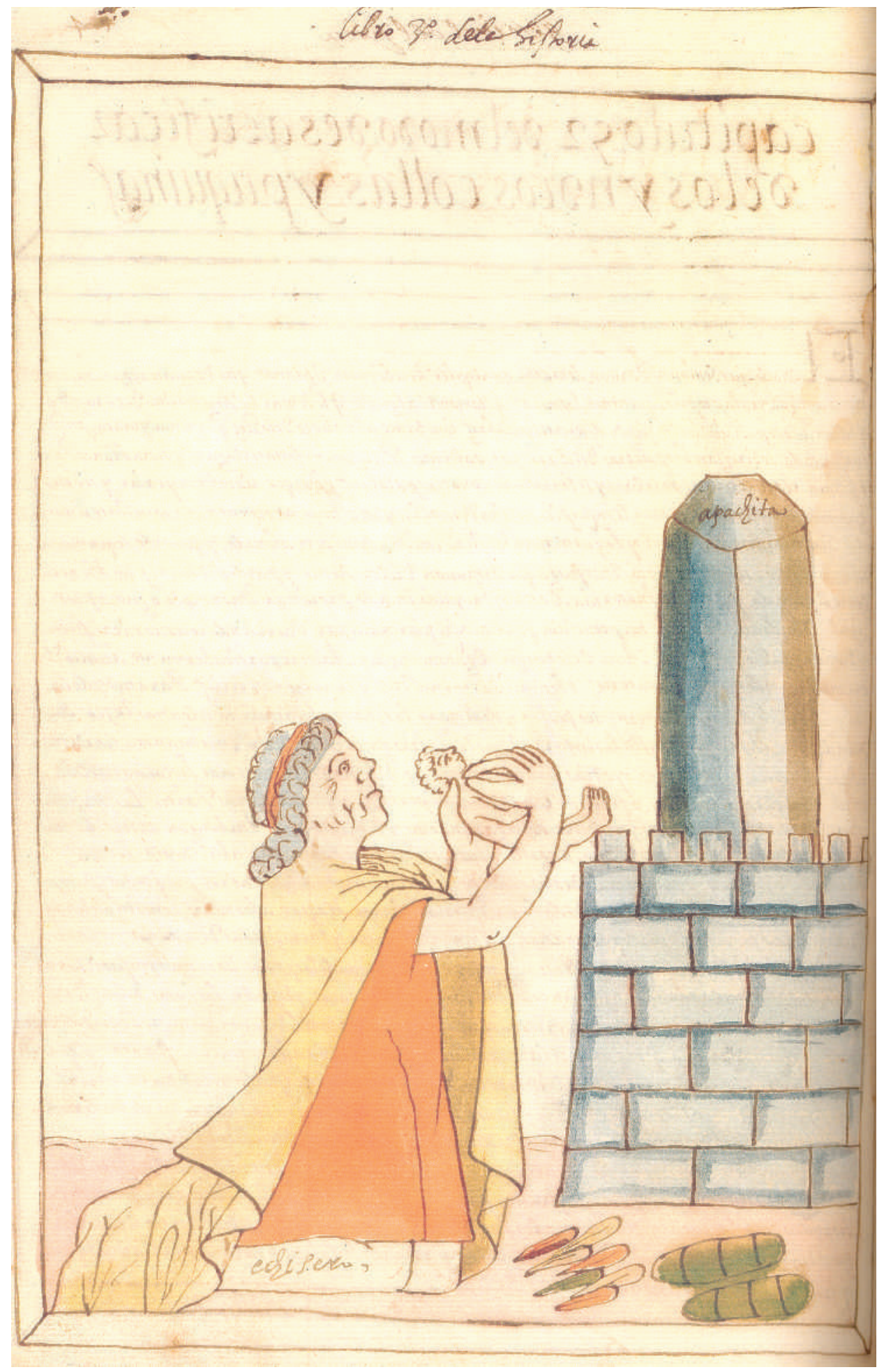

Figura 16. Ilustración de Martín de Murúa, siglo Xvi, de lo que probablemente fue una saywa (2004 [1615]: 105v). Nótese su parecido con la pieza de basalto encontrada en Tocomar. Figure 16. Illustration by Martín de Murúa, 16th century, probably depicting a saywa (2004 [1615]: 105v). Note its resemblance to the piece of basalt found in Tocomar. 
Sin embargo, a la vez abre la puerta a un conjunto de preguntas que, por el momento, no estamos en condiciones de responder. En primer lugar, estas columnas aparentemente no estarían relacionadas con el tipo de "lectura" astronómica que suelen describir los cronistas coloniales para las del Cuzco. En general, los datos de esas columnas se refieren a un sistema de medición donde estas se sitúan a distancia (horizonte), y donde el astro (principalmente el sol) sale o se pone por entre medio de ellas (Betanzos 1987 [1551]; Anónimo1906 [15701584]; Cobo 1964 [1653]; Williams 2001). Las saywas de Atacama, parecen estar obedeciendo a una lectura in situ que se parece más a la función astronómica del ushnu como gnomon. Suponemos que las columnas del desierto de Atacama tenían el propósito de ser leídas desde el camino. En ese sentido, parecen estar representando un calendario astronómico "inscrito" en la tierra y específicamente en el Qhapaq Ñan. Una vez más toma sentido la idea de que los principios ordenadores del espacio y el tiempo se aplicaban a los Caminos del Inca $y$, a la vez, se sacralizaban con la presencia o el paso de una divinidad celeste por sobre los "mojones del Inca".

Por otra parte, en ambos casos descritos destacan las características, no solo desérticas, sino también carentes de población inmediatamente cercana. Se trata de espacios "vacíos" (sensu Berenguer \& Pimentel 2006), ubicados fuera de los centros poblados y a una importante distancia de los principales centros administrativos inkaicos correspondientes. ${ }^{10}$ ¿Por qué razón, entonces, las columnas fueron emplazadas allí?

Pero, por otro lado, y más allá de su función simbólica y ritual, surge la pregunta respecto a la función "operativa" de las saywas del camino. Como ya se dijo, estas fueron llamadas generalmente tupus por los españoles, concepto que no era equivocado. Ya hemos mencionado sus posibles alcances como referentes de medición de distancias y de territorialidades. Pero, simultáneamente, estaban midiendo también el "tiempo", es decir un tiempo calendárico asociado a fechas muy significativas del ciclo anual del sol, como los solsticios. Es muy posible que las saywas de Tocomar constituyeran también un deslinde o frontera sacralizada, ya fuera para la mantención del camino y por tanto de los deberes hacia el Estado en pleno despoblado, o también para delimitar el acceso a ciertos recursos de valor. En definitiva, aunque las próximas etapas de la investigación están aún pendientes, creemos que los sitios astronómicos de Lasana y de Tocomar abren un camino aún inexplorado en los estudios del Qhapaq Nan del norte de Chile. Sin embargo, ambos sitios son muy diferentes entre sí. Mientras uno presenta un largo alineamiento de, por lo menos, cinco columnas, el otro consiste solo en dos saywas, unidas por una hilera de piedras. ¿Por qué el uso de formas y tecnologías diferentes?

Hemos podido constatar, por otra parte, que el estudio del Qhapaq Ñan desde una metodología interdisciplinaria, que incorpore los aportes de la etnohistoria, la arqueología y la astronomía, entre otros, puede abrirnos perspectivas de análisis que no habíamos sospechado en los inicios de esta investigación. El Qhapaq Nan representaba un importante eje ordenador y articulador de la estructura de poder del Tawantinsuyu y, en ese contexto, las saywas no eran elementos azarosos. Se trataba de estructuras cargadas de significado que pudieron responder a distintas funciones o técnicas de lectura según el contexto y las características con que se presentaran.

Los alineamientos de saywas en los Caminos del Inka estaban en directo diálogo o relación con la organización de los astros en el espacio celeste y, por tanto, con el calendario andino. La estrecha asociación e interdependencia entre el orden celeste y el terrestre se materializaba en un discurso cosmológico estatal y en dispositivos específicos aplicados al paisaje.

Los Caminos del Inca representaban la presencia del poder estatal hasta en los más remotos confines del Imperio y reflejaban una forma de organizar culturalmente el espacio geográfico, el espacio social y el orden cósmico. Si bien el desierto de Atacama fue considerado por los españoles solo como una necesaria ruta de paso y como un territorio vacío, extremadamente inhóspito e improductivo (Sanhueza 2005), desde la mirada andina constituyó un espacio de significados complejos. Ameritó la inversión de energía humana y de la ingeniería estatal para sacralizar determinados lugares o espacios cuidadosamente seleccionados, donde marcó la presencia de la divinidad solar ya no solo en los grandes centros urbanos o administrativos, sino también en pleno despoblado. 
NOTAS

${ }^{1}$ En el trabajo citado hemos discutido más prolijamente el concepto de "legua del Inca" y sus posibles interpretaciones, incluyendo en dicho análisis la capacidad de desplazamiento de los chasquis, como posible unidad de medición.

2 "Bolo: Trozo de palo labrado, de forma alargada, con base plana para que se tenga derecho" (RAE, S.V.).

${ }^{3}$ Un estado de altura correspondía, aproximadamente, a la estatura de un hombre.

${ }^{4}$ Estas columnas descritas por el cronista Anónimo son las únicas que Zuidema (2010) considera efectivamente de uso astronómico.

${ }^{5}$ En este aspecto, el autor discrepa de la información otorgada por Cobo, quien sostiene que al menos algunos de estos pilares o huacas astronómicas estaban alineadas dentro de la estructura del sistema de ceques (Cobo 1964 [1653]: 172; Cobo en Zuidema 1966: 30).

${ }^{6}$ Cenit: punto en el cielo ubicado directamente arriba de un determinado observador, es decir, configurando un ángulo de $90^{\circ}$.

${ }^{7}$ Hacia el oeste se apreciaba una primera columna en muy malas condiciones de conservación, por lo que hasta no tener la completa certeza, decidimos no incorporarla a nuestro registro base.

${ }^{8}$ Agradezco a la antropóloga Marinka Núñez por haber puesto toda su energía y habilidad en terreno para ayudarme a encontrar este sitio arqueológico.

${ }^{9}$ Agradezco al arqueólogo Wilfredo Faúndez, especialista en líticos, por su análisis de la pieza mencionada.

${ }^{10}$ En efecto, las saywas de Lasana se encuentran a unos $14 \mathrm{~km}$ al norte del poblado y pukara homónimos y a unos $40 \mathrm{~km}$ al noroeste del centro administrativo Inka de Turi (Berenguer 2009). A su vez, las saywas de Tocomar, del llamado Gran Despoblado de Atacama, no cuentan con población cercana y las distantes cabeceras inkas se encuentran en las localidades de Catarpe (San Pedro de Atacama), ubicada a unos $250 \mathrm{~km}$ al norte, y el valle de Copiapó, a otros tantos kilómetros de distancia hacia el sur.

RECONOCIMIENTOS Muy especialmente al Dr. Marco Curatola, por sus comentarios, críticas y estímulo. Agradezco también a todas las personas que participaron de una u otra manera en este trabajo: Juan Cortés, Sergio Martín (astrónomos), Marinka Núñez (antropóloga),
Pedro Hernández (geógrafo), José Berenguer, Carlos González, Willy Faúndez, Gonzalo Pimentel, Lautaro Núñez, Felipe Criado-Boado, José Pino, Christian Vitry, Valentina Figueroa, Pablo Mignone (arqueólogos).

\section{REFERENCIAS}

Anónimo, 1906 [1570-1584]. Discurso de la sucesión y gobierno de los Incas. En Juicio de límites entre Perú y Bolivia. Prueba presentada al gobierno de la República Argentina. "Chunchos". V. Maurtúa, Ed., Vol. viII, pp. 149-165. Buenos Aires: Imprenta, Litografía y encuadernación de G. Kraft.

Bauer, B. \& D. Dearborn, 1998. Astronomía e imperio en los Andes. Cuzco: Centro Bartolomé de las Casas.

Berenguer, J., 2007. El Camino Inka del Alto Loa y la creación del espacio provincial en Atacama. En Producción y circulación prehispánica de bienes en el sur andino, A. Nielsen, C. Rivolta \& V. Seldes, Comps., pp. 413-435. Córdoba: Brujas.

Berenguer, J., 2009. Chile bajo el imperio de los inkas. Santiago: Museo Chileno de Arte Precolombino.

Berenguer, J. \& G. Pimentel, 2006. Arqueología de los espacios vacíos: una aproximación internodal a las relaciones intersocietales. En Actas del XVII Congreso Nacional de Arqueología Chilena, Vol. II, pp. 1305-1308. Santiago: Sociedad Chilena de Arqueología.

Berenguer, J.; CÁceres, I., Sanhueza, C. \& P. Hernández, 2005. El Qhapaq Nan en el Alto Loa. Región de Antofagasta. Un estudio micro y macro arqueológico. Estudios Atacameños 29: 7-39.

Bertonio, L., 1984 [1612]. Vocabulario de la lengua aymara. Cochabamba: Ceres.

Betanzos, J., 1987 [1551]. Suma y narración de los Incas. M. C. Martín Rubio, Ed. Madrid: Atlas.

Castro, V. \& V. VArela, 2004. De cómo camina el sol durante junio, de lo que se ve en el cielo y de lo que se comenta y se practica en la tierra. Oralidad y rituales en la subregión del Río Salado, Norte de Chile. En Etno y Arqueo-astronomía en las Américas, M. Bocass, J. Broda \& G. Pereira, Eds., pp. 285-298. Santiago: Universidad de Chile.

Cieza de león, P., 1973 [1550]. La crónica del Perú. Lima: PEISA-Biblioteca Peruana.

Cieza de león, P., 1986 [1553]. Crónica del Perú (segunda parte) o señorío de los Incas. Lima: Pontificia Universidad Católica del Perú-Academia Nacional de la Historia.

Сово, В., 1964 [1653]. Historia del Nuevo Mundo. Biblioteca de Autores Españoles. Tomo XCII, Volúmenes I-II. Madrid: Atlas.

GARCILASO DE LA VEGA, I., 1995 [1609]. Comentarios reales de los Incas. Tomos I-II. Ciudad de México: Fondo de Cultura Económica. 
GonZÁlez, D., 1952 [1608]. Vocabulario de la lengua de todo el Perú llamada lengua Qqichua o del Inca. Lima: Universidad Nacional de San Marcos.

GonzÁLEz, C., 2007. Qhapaq Ñan en el extremo meridional del despoblado de Atacama, Chile. En Actas del XvI Congreso Nacional de Arqueología Argentina, Tomo II, pp. 511-518. San Salvador de Jujuy: Universidad Nacional de Jujuy.

Guamán Poma de Ayala, F., 1992 [1615]. Nueva crónica y buen gobierno. J. Murra \& R. Adorno, Eds. Ciudad de México: Siglo XXI Editores.

Hyslop, J., 1992. Qhapaqñam, el sistema vial incaico. Lima: Instituto Andino de Estudios Arqueológicos-Petróleos del Perú.

IrIbARREN, J. \& H. Bergholz, 1972-1973. El Camino del Inca en un sector del Norte Chico. En Actas del VI Congreso de Arqueología Chilena, H. Niemeyer, Ed., pp. 229-266. Santiago.

LYNCH, T., 1995-1996. Inka roads in the Atacama: effects of later use by mounted travellers. Diálogo Andino 14-15: 189-203.

LYNCH, T. \& L. NúÑEZ, 1994. Nuevas evidencias inkas entre Kollahuasi y Río Frío (I y II Regiones de Chile). Estudios Atacameños 11: 145-164.

MurúA, M., 2004 [1590]. Códice Murúa: historia y genealogía de los reyes incas del Perú del padre mercedario Fray Martín de Murúa: códice Galvin, J. Ossio, Ed. Madrid: Testimonio Compañía Editorial.

Niemeyer, H. \& M. Rivera, 1983. El Camino del Inca en el despoblado de Atacama. Boletín de Prehistoria de Chile 9: 91-193. Arica.

NúÑEZ, P., 1981. El Camino del Inca. Creces 10 (2): 49-57. Santiago.

PINO, J., 2005. El ushnu y la organización espacial astronómica en la sierra central del Chinchaysuyu. Estudios Atacameños 29: 143-161.

Real Academia Española de la Lengua, 2014. Diccionario de la Lengua Española. <dle.rae.es>

SAnhueza, C., 2004. Medir, amojonar, repartir: territorialidades y prácticas demarcatorias en el camino incaico de Atacama (II Región, Chile). Chungara 36 (2): 481-492.

SANhueza, C., 2005. Espacio y tiempo en los límites del mundo. Los Incas en el despoblado de Atacama. Boletín del Museo Chileno de Arte Precolombino 10 (2): 51-77.

Santa Cruz Pachacuti, J., 1993 [1613]. Relación de antigüedades deste reyno del Piru. Cusco: Institut Francais D’Études Andines-Centro de Estudios Regionales Andinos Bartolomé de Las Casas.

SANto Tomás, D., 1951 [1560]. Lexicón. Lima: Universidad Nacional de San Marcos.

Sarmiento de Gamboa, P., 1942 [1572]. Historia de los incas. Buenos Aires: Emecé

Urton, G., 1981. At the crossroads of the earth and the sky. An Andean cosmology. Austin: University of Texas Press.

Urton, G., 1984. Chuta: el espacio de la práctica social en Pacariqtambo, Perú. Revista Andina 2 (1): 7-43.
Urton, G., 2006. En el cruce de rumbos de la tierra y el cielo. Cusco: Centro de Estudios Regionales Andinos Bartolomé de Las Casas.

Vitry, C., 2008. Los espacios rituales en las montañas donde los inkas practicaron sacrificios humanos. En Paisagens Culturais. Contrastes sul-americanos, C. Terra \& R. Andrade, Eds., pp. 47-65. Rio de Janeiro: Universidade Federal do Rio de Janeiro.

WiLliams C., 2001. Sukankas, quipus y ceques: el tiempo y la sacralización del espacio en el Cusco. Revista del Museo Nacional XuIx: 123-162. Lima.

Zecenarro, G., 2001. Arquitectura arqueológica en la quebrada de Thanpumachay. Cuzco: Municipalidad del Cuzco.

Zuidema, T., 1966. El calendario inca. En Actas y Memorias del XXXVI Congreso Internacional de Americanistas, Volumen II, pp. 25-30. Sevilla.

Zuidema, T., 1989. Reyes y guerreros. Ensayos de cultura andina. Lima: FOMCIENCIAS.

Zuidema, T., 2010. El calendario inca. Tiempo y espacio en la organización ritual del Cuzco. La idea del pasado. Lima: Fondo Editorial del Congreso del Perú-Fondo Editorial Pontificia Universidad Católica del Perú.

Zuidema, T. \& G. URTon, 1976. La constelación de la llama en los Andes peruanos. Allpanchis 9: 59-119. Cuzco. 